\title{
Sarah S. Stith*
}

\section{Effects of work requirements for food assistance eligibility on disability claiming}

\begin{abstract}
Between 2010 and 2017, 42 U.S. states added work requirements as a food assistance eligibility criterion for Able-Bodied Adults Without Dependents (ABAWDs). Another U.S. public assistance program, Supplemental Security Income (SSI), provides food assistance without a work requirement, along with cash transfers and health insurance. Therefore, individuals for whom working is difficult may be induced to opt out of the labor force and into SSI in order to maintain access to food assistance. This study is the first to examine whether work requirements associated with food assistance eligibility lead to an increase in SSI applications and receipts. Based on difference-in-differences and event study analyses of comprehensive administrative claims data from the Social Security Administration and survey data from the Current Population Survey, this study finds evidence of lagged effects on SSI applications overall, and reduced Supplementary Nutritional Assistance Program (SNAP) receipts followed by a delayed smaller increase in SSI receipts among individuals with self-reported disabilities. While most SSI applications induced by SNAP-related work requirements appear to be unsuccessful, a small, vulnerable population may move out of the workforce and into SSI in response to the implementation of work requirements.
\end{abstract}

\begin{tabular}{|c|c|}
\hline Current version: & January 10, 2022 \\
\hline Keywords: & $\begin{array}{l}\text { disability, public assistance, work requirement, food stamps, time limit } \\
\text { waiver, welfare }\end{array}$ \\
\hline JEL-codes: & $\mathrm{H} 53, \mathrm{I38}, \mathrm{J} 22$ \\
\hline Corresponding author: & $\begin{array}{l}\text { Sarah S. Stith } \\
\text { ssstith@unm.edu, ORCID: 0000-0003-0311-5674 }\end{array}$ \\
\hline
\end{tabular}

Department of Economics, University of New Mexico, MSC05 3060, Albuquerque, NM 87131-1161, United States

(c) The Author(s). 2022 Open Access This article is distributed under the terms of the Creative Commons Attribution 4.0 International License (http://creativecommons.org/licenses/by/4.0/), which permits unrestricted use, distribution, and reproduction in any medium, provided you give appropriate credit to the original author(s) and the source, provide a link to the Creative Commons license, and indicate if changes were made. (0.) Cite as: Stith. IZA Journal of Labor Economics (2022) 11:02. 


\section{Acronyms}

$\begin{array}{ll}\text { ABAWD: } & \text { Able-Bodied Adult Without Dependents } \\ \text { ACA: } & \text { Patient Protection and Affordable Care Act } \\ \text { AFDC: } & \text { Aid to Families with Dependent Children } \\ \text { CPS: } & \text { Current Population Survey } \\ \text { CPS - ASEC: } & \text { Current Population Survey - Annual Social and Economic Supplement } \\ \text { FNS: } & \text { Food and Nutrition Service } \\ \text { FPL: } & \text { Federal Poverty Line } \\ \text { PDMP: } & \text { Prescription Drug Monitoring Program } \\ \text { PRWORA: } & \text { Personal Responsibility and Work Opportunity Reconciliation Act of } 1996 \\ \text { SAMWD: } & \text { Social Security Administration State Agency Monthly Workload Data } \\ \text { SNAP: } & \text { Supplemental Nutrition Assistance Program } \\ \text { SSA: } & \text { Social Security Administration } \\ \text { SSDI: } & \text { Social Security Disability Insurance } \\ \text { SSI: } & \text { Supplemental Security Income } \\ \text { TANF: } & \text { Temporary Assistance for Needy Families } \\ \text { USDA: } & \text { United States Department of Agriculture }\end{array}$

\section{Introduction}

Welfare recipiency can disincentivize some individuals from entering or returning to the workforce. As a result, public food assistance eligibility in the United States is contingent upon individuals meeting employment-related requirements, such as participating in job training programs or working or volunteering for a minimum number of hours. For able-bodied adults without dependents, such requirements are particularly strict with fewer non-employment options available to meet the requirements, especially when local unemployment rates are low. Unfortunately, particularly when economic conditions are good, those who remain unemployed tend to be among the least employable. Some individuals receiving food assistance surely are among these "least employable," so that work requirements do not induce employment but rather force them to seek out other means of sustaining themselves, e.g., through other public assistance programs. The incidence of such effects is likely to be concentrated among individuals with characteristics that limit employment opportunities or increase eligibility for public assistance programs, such as having a disability or very low income. This paper tests whether increased stringency in work requirements for food assistance eligibility led to increases in applications for and receipt of disability-related public assistance targeted at low-income individuals. As disability-related public assistance is substantially more generous than food assistance alone, such a shift in program participation could have costly fiscal implications.

In the United States, the Personal Responsibility and Work Opportunity Reconciliation Act of 1996 (PRWORA) introduced time limits of 3 months within 3 years for receipt of food assistance benefits by able-bodied adults (aged 18-49) without dependents (ABAWDs). Once the time limit has been exceeded, the ABAWD must work a minimum of $20 \mathrm{~h} /$ week, while maintaining an income level $<130 \%$ of the Federal Poverty Level in order to continue to receive food assistance benefits through the Supplemental Nutrition Assistance Program (SNAP). 
In acknowledgment that the ABAWD requirements would be difficult to meet when few jobs are available, the PRWORA allows for ABAWD time limits and associated work requirements to be suspended if unemployment is sufficiently high. A "time limit waiver" entails that ABAWD work requirements and the associated time limit on SNAP receipt are no longer applicable in the region which granted the waiver. Waivers are typically assessed on an annual basis. ${ }^{1}$

Those with a disability are exempt from SNAP work requirements. To be classified as disabled in the context of SNAP enrollment, an individual must be receiving federal disability payments under the Social Security Act [including Supplemental Security Income (SSI) and Social Security Disability Insurance (SSDI)], or alternatively, receiving state disability payments based on SSI rules. ${ }^{2}$ Apart from disability requirements, SSI only is available to low-income individuals with assets worth $<\$ 2,000$ for individuals ( $\$ 3,000$ for couples). SSDI requires a sufficient work history for eligibility. The implementation of ABAWD work requirements could thus incentivize SNAP recipients, who are not enrolled in a disability program, to apply for disability benefits to be exempt from the newly implemented work requirements, in addition to gaining benefits in terms of direct payments and healthcare. Because SSDI requires sufficient work history for eligibility, SSI is more likely to be impacted by individuals for whom obtaining employment is difficult, and hence is the focus of the current study. ${ }^{3}$ Specifically, I test whether ABAWD work requirements increase the number of SSI applicants and recipients using the administrative claims data and whether ABAWD work requirements decrease SNAP receipt and increase SSI receipt using national survey data.

My sample period begins with eight states having work requirements in place in 2010. By the end of my sample period in 2017, all states except Rhode Island had work requirements (Rhode Island implemented a work requirement in 2017). The administrative SSI claims data do not include receipt of SNAP alone or demographic information. Therefore, I use survey data from the Current Population Survey (CPS) to measure self-reported SNAP and SSI receipt overall and in the population most likely to attempt to obtain SSI through a qualifying disability, individuals with self-reported disabilities and income $<150 \%$ of the federal poverty line, the approximate income eligibility requirement for both SNAP and SSI. (The SNAP income threshold is $130 \%$ of the FPL).

Standard difference-and-differences analyses and event studies show little effect from work requirements on SSI applications or receipt, although treatment measures weighted by the affected population show a reduction in SNAP receipt. However, diagnostics suggest that substantial heterogeneity exists in treatment effects, depending on how units are compared (Goodman-Bacon, 2021). To correct for the issues associated with applying difference-indifferences techniques in the presence of variation in treatment timing and multiple time periods, I follow recent work by Callaway and Sant'Anna (2021). The adjusted event studies show a gradual effect that increases over time for SSI applications, peaking at a $10.6 \%$ increase from the mean or 3.6 additional applications/10,000 population. Overall SSI recipiency does

1 https://www.fns.usda.gov/snap/ABAWD/waivers. Accessed 08/03/20.

2 Some states supplement federal SSI payments, while others administer their own SSI programs. Details do not appear readily available with individuals directed by the federal Social Security Administration to contact their state offices. https://www.ssa.gov/ssi/text-benefits-ussi.htm. Accessed 08/05/20. The University of Kentucky Center for Poverty Research stopped recording this information in 2011.

3 while SSDI applies only to individuals with sufficient work history (worked roughly 25 percent of their adult life and 5 of the last 10 years before disability onset). 
not appear to be affected using either administrative claims data or the CPS data. Focusing on SNAP and SSI receipt among individuals with self-reported disabilities or earning $<150 \%$ of the FPL, I find that rates of SNAP receipt among individuals with self-reported disabilities experience a statistically significant decrease of as much as $24 \%$ from the mean in the first 2 years following policy implementation with a potentially related, smaller, marginally statistically significant increase of $23 \%$ in the likelihood of reporting SSI receipt that becomes evident in the fifth year post-policy change. With processing times often in years, a delayed SSI recipiency effect is consistent with the decline in SNAP receipt in the CPS data and the increase in SSI applications from the administrative data. Lower-income individuals exhibit a marginally significant decline in SNAP receipt, but no corresponding effect on SSI receipt exists, potentially reflecting the necessity of having a qualifying disability to apply for SSI.

This study contributes to the literature on the effects of public assistance-related work requirements and whether individuals substitute across public assistance programs. Theoretical work predicts that work requirements deter enrollment in the affected welfare program (Besley and Coate, 1992), which is in line with the results in this paper showing a decline in SNAP receipt among those with self-reported disabilities but is not supported by the insignificant overall effects on SNAP receipt. The literature on specifically SNAP-related work requirements using national U.S. data so far has focused on primary enrollment effects and employment effects. SNAP enrollment generally decreases following the implementation of work requirements (Ganong and Liebman, 2018; Brantley et al., 2020), but employment effects are limited and vary across demographic groups (Harris, 2020; Gray et al., 2021; Wasif and Stith, 2020). The decrease in enrollment without an increase in employment suggests some individuals may be opting out of the workforce (Wasif and Stith, 2020), possibly to enroll in other public assistance programs. This study documents small and insignificant overall spillover effects from SNAP-related work requirements on SSI receipt, but larger, more significant effects among a particularly affected subgroup, which may help explain the mixed results on substitution across welfare programs found in empirical work. Burns and Dague (2017) find substitution between Medicaid obtained via the Affordable Care Act expansions and SSI participation, but Baicker et al. (2014) do not. Other studies find substitution between TANF/ AFDC and SSI (Garrett and Glied, 2000; Schmidt and Sevak, 2004).

I contribute well to the literature on potential factors driving SNAP and SSI receipt, which include economic conditions, employment opportunities, especially among less-skilled workers (Autor and Duggan, 2003; Schmidt, 2012; Ganong and Liebman, 2018; Thomas et al., 2019), and for SSI, local area earnings (Black et al., 2002; Charles et al., 2018; Vachon, 2015), as well as unrelated factors, which influence budget constraints, such as cigarette taxes in the case of SNAP enrollment (Rozema and Ziebarth, 2017). A 2019 study by the SSA notes a decline in SSI applications (SSA, 2019b), at least before the COVID pandemic. None of these studies addresses the possible spillover effects on SSI from SNAP-related work requirements. The current study also evaluates SNAP and SSI receipt among a particularly vulnerable population, those most likely to be on the margin between applying for and potentially obtaining disability versus continuing to be counted among the "able-bodied" population.

The results of this study are relevant to recent and proposed changes in U.S. federal public assistance programs. In December 2019, the Trump administration proposed making SNAP-related ABAWD waivers more difficult to obtain. Historically, a local 
unemployment rate exceeding the national average unemployment rate by $20 \%$ qualified a county or state for a time limit waiver, but the December 2019 administrative change would have added the qualification that the unemployment rate must also exceed $6 \%$. The change was challenged in the courts and the Trump administration ultimately chose to wait on attempting to add the qualification, given pandemic- and protest-related national emergencies (Fadulu, 2020). Other public assistance programs also have work requirements that could affect individuals on the margin of continuing enrollment versus opting into a disability assistance program. Understanding whether SNAP work requirements shift claimants to SSI disability benefits and which recipients are most likely to be affected is also of policy relevance from a government expenditure standpoint, given the much more extensive benefits afforded under SSI.

\section{Institutional Background}

This study looks at the intersection of two large federal programs: the Supplemental Nutrition Assistance Program (SNAP), run through the U.S. Department of Agriculture's Food and Nutrition Service (FNS), and Supplemental Security Income (SSI), which is administered by the Social Security Administration (SSA).

Each state administers its own SNAP program, following federal guidelines. Typically, households can not only apply in person at local offices but also by mail, via facsimile, or online. Eligibility is based on residency, immigration status, household composition, income and resources, and deductible expenses. Eligible households receive an electronic benefits card that can be used to purchase food but excludes alcoholic beverages, cigarettes, vitamin supplements, non-food grocery items such as household supplies and hot foods. In July 2020, 241,793 retailers were authorized to participate in the program. ${ }^{5}$ In 2019, 38 million individuals received SNAP benefits at an average amount of $\$ 1.40 /$ meal or $\$ 127 /$ month for an individual and \$256 for a household (CBPP, 2019a).

For households receiving SNAP based on income alone, they typically must reapply every 6-12 months. Households receiving SNAP based on disability only have to reapply every 12-24 months. SNAP benefits are automatically terminated if the household does not reapply, but can also be denied, suspended, or terminated by the state SNAP administrator. Households may appeal these decisions through the Department of Human Services' Bureau of Hearings and Appeals, which receives approximately 100,000 appeals/year. ${ }^{6}$

Concerns exist that individuals receiving SNAP and other forms of welfare are disincentivized to work. Perhaps the largest single piece of legislation enacted to incentivize work rather than public assistance was the PRWORA, which expanded incentives for states to move public assistance beneficiaries from welfare receipt back to employment.

4 If the national unemployment rate were four percent, an unemployment rate of 4.8 percent would be 20 percent higher than the national rate, and thus that area would have qualified for a time limit waiver under the old rule. Under the new rule, the local unemployment rate would have to both exceed the national rate by 20 percent and exceed 6 percent in absolute terms, meaning that the same area with 4.8 percent unemployment would no longer qualify for a time limit waiver.

5 USDA SNAP Store Locations. https://usda-fns.hub.arcgis.com/datasets/USDA-FNS::snap-store-locations?geometry=48.912\%2C-9.798\%2C19.643\%2C74.211 Accessed 07/09/20.

6 https://www.dhs.pa.gov/about/DHS-Information/Pages/Hearing-and-Appeals-Process.aspx. Accessed 07/09/20. 
Relevant to this study, the PRWORA included additional work requirements for ABAWDs receiving SNAP. These work requirements are dependent on local economic conditions and are waived at the county level. According to the Food and Nutrition Service (FNS), during the sample period from 2010 to 2017, the criteria by which states could qualify for a time limit waiver were: (1) a recent 12-month unemployment rate $>10 \%$ overall in the county or state, (2) a recent 3-month unemployment rate $>10 \%$, (3) designation as a Labor Surplus Area ${ }^{7}$ by the Department of Labor; (4) qualification for extended unemployment benefits, or (5) a recent 24-month average unemployment rate $20 \%$ above the national average for the same 24-month period (SNAP, 2015). Due to the Great Recession, in 2008, no states had work requirements. In 2010, at the start of the sample period, eight states had work requirements reinstated in at least some counties. By the end of the sample period in 2017, all states except Rhode Island had work requirements in place in at least some counties. (Rhode Island followed in 2018).

SNAP has two sets of work requirements. Even before the PRWORA, applicants between the ages 16 and 59 and able to work needed to meet general work requirements to receive SNAP benefits. The general work requirements include registering for work, participating in SNAP Employment and Training or workfare if assigned by their state SNAP agency, taking a suitable job if offered, and not voluntarily quitting a job or reducing work hours $<30$ a week without a good reason. The work requirement for ABAWDs added by the PRWORA differs in that an individual can only receive SNAP benefits for $>3$ months within 3 years (the time limit) if that person finds employment. In other words, if an individual is aged 18-49, does not have any dependents, and can work, but does not find a job within the time limit, that person loses SNAP benefits while other SNAP recipients do not. States can also voluntarily institute work requirements, but these are not tracked in the USDA correspondence on which the work requirements data used in this study are based. The Center for Budget and Policy Priorities reports three instances where states implemented work requirements before exhausting their time limit waivers through the USDA (CBPP, 2019c).

The USDA allows states to exempt up to $15 \%$ of ABAWDs from work requirements, with some states taking advantage of these exemptions while others do not. Based on correspondence from the USDA to states between 2012 and 2017, not all states that could use exemptions did. Even states that used exemptions typically did not use the full 15\%. In 2012, four of eleven states with work requirements used exemptions, exempting about $1.6 \%$ of their ABAWDs on average. In 2017, 32 of 50 states with work requirements used exemptions, exempting about $3.6 \%$ of their ABAWDs on average. States also can be banned from using exemptions due to exempting $>15 \%$ of their ABAWD population in previous years. Both Florida and New Mexico were unable to take exemptions during the entire sample period of this study, due to exempting far $>15 \%$ of their ABAWDs in 2009.

Individuals with disabilities that prevent them from working are not subject to work requirements for SNAP and may be able to obtain SNAP and additional benefits through SSI. SSI is limited to individuals with assets of $<\$ 2,000$ or couples with assets of $<\$ 3,000$, and individuals between the ages of 18 and 49 must meet the SSA's disability criteria. Disability is defined as an inability to participate in any "substantial gainful activity," which effectively

$7 \quad$ A jurisdiction is classified as a labor surplus area when its average unemployment rate is at least 20 percent above the average unemployment rate for the nation during the previous two calendar years, with a ceiling of 10 percent and a floor of 6 percent for periods of very high or low national unemployment. 
meant earning $>\$ 1,260 /$ month in $2020 .{ }^{8}$ The disabling condition must be terminal or have existed/be expected to exist for 12 months or more.

Applying for SSI can be done in person or online and an extensive, sometimes multi-year, appeals process exists. Approximately half of SSI applicants initially are denied an appeal, and only about $40 \%$ of all applicants eventually qualify (SSA, 2020b).

In 2019 , the maximum SSI payout was $\$ 771 /$ month for individuals and $\$ 1,157$ for couples with 7.97 million individuals receiving federal SSI benefits of, on average, \$549/month (SSA, 2019a). Work on uptake of SNAP and SSI among the elderly suggests that cash benefits, such as those available through SSI, may be worth more than in-kind transfers, such as the SNAP, further increasing the relative benefits of SSI versus SNAP alone (Coe and Wu, 2014). SSI recipients also qualify for Medicaid immediately in most states and almost all SSI recipients qualify for SNAP. SSI benefits commence after 1 month post-application when an individual is found eligible.

\section{Data and Variables}

To measure the effect of work requirements on disability claiming, I use multiple data sources. The treatment variables are based on USDA correspondence, obtained in portable document format (pdf), while the outcome variables come from two primary sources, the SSA State Agency Monthly Workload Data (SAMWD) and the Current Population Survey (CPS). The USDA correspondences were graciously shared with me by Timothy Harris at Illinois State University, the SAMWD were downloaded from Social Security Administration website, ${ }^{9}$ and the CPS were obtained from the IPUMS-CPS database. ${ }^{10}$

The implementation or waiver of work requirements occurs at multiple levels. It can happen at the county level, where multiple counties may be grouped to form a unit, or the entire state can act as a single unit. Work requirements are typically enacted for a full year, but in some cases may be enacted partway through the year. In a few states, it appears the USDA reinstated the work requirement for a month or two before waiving it in the subsequent year. USDA correspondence also indicates changes in the counties affected by the work requirement partway through the year, but these circumstances appear limited. At the state level, the CBPP lists seven instances when work requirements were waived for only part of the year during the sample period (CBPP, 2019b). The SNAP work requirement information used to create the treatment variable in this study was assembled from correspondence between the United States Department of Agriculture's Food and Nutrition Service (FNS) and individual states pertaining to the application and granting of ABAWD time limit waivers between 2010 and 2017. Of the 50 states, eight states already had work requirements implemented by the beginning of the sample period, with the other 43 states implementing work requirements during the period 2010-2017, providing substantial variation within most states over time. (Only two states, Virginia and West Virginia reverse their work requirements during this period). The largest work requirement implementation happened in the year 2016 when ABAWD time limit waivers for 22 states expired and were not renewed. Figure 1 shows the number of states with

8 Individuals with blindness as their qualifying disability are allowed to earn up to $\$ 2,110$ per month in 2020 (SSA, $2020 \mathrm{a}$ ).

9 SSA State Agency Monthly Workload Data, https://www.ssa.gov/disability/data/ssa-sa-mowl.htm

10 IPUMS-CPS, University of Minnesota, www.ipums.org 
Figure 1 States with work requirements by year.

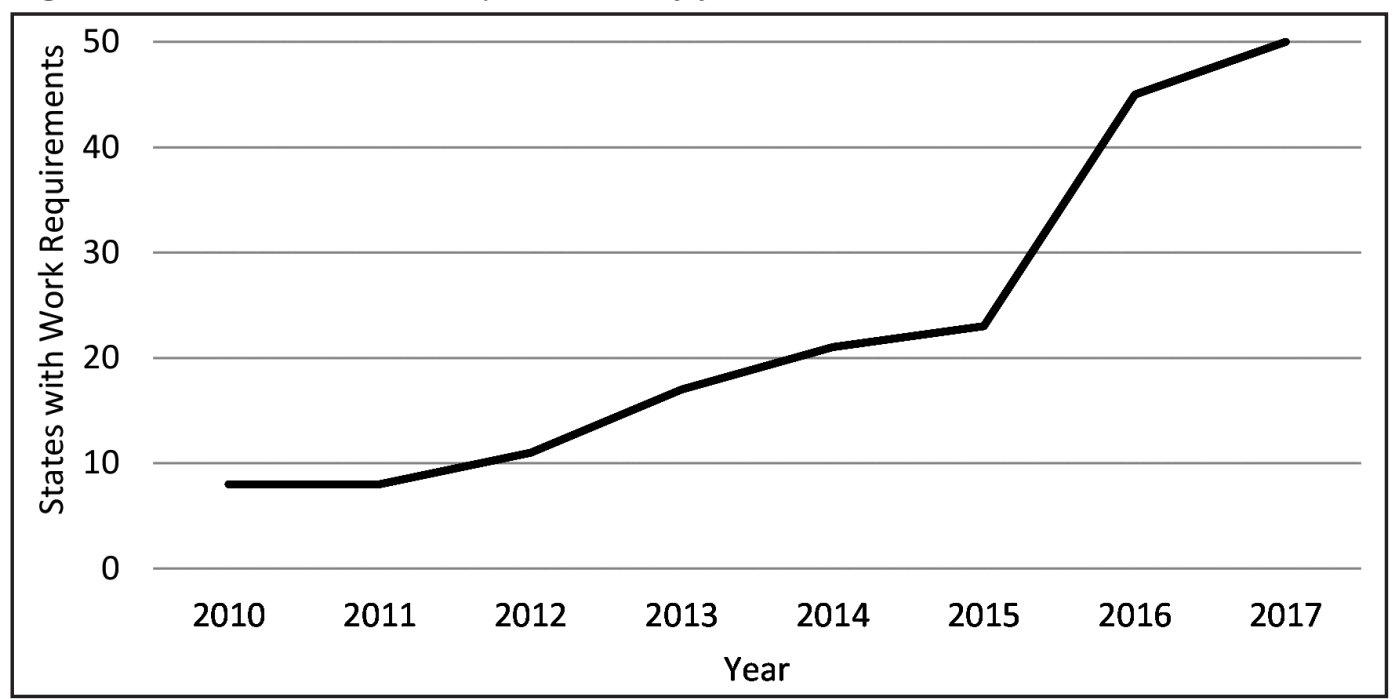

Notes: Data are from USDA correspondence to states regarding their work requirement waivers.

work requirements by year (see Table A1 in Appendix further details the specific years in which states implemented work requirements).

I collapse the treatment variable at the state unit for the regression analysis. For the statelevel treatment variable, states are regarded as treated if any county within the state has an ABAWD work requirement. In the robustness checks, I further weight the state-level treatment variable with the proportion of the state population that likely is affected by the work requirement. I do so in two ways - first, using the CPS, I calculate the number of ABAWDs living in counties with work requirements and divide that by the total number of ABAWDs with county information reported. Because county information is not reported for many households in the CPS, I also use the percentage of counties affected by the work requirement as another measure of the intensity of the treatment at the state level.

The SAMWD is the only source for data on applications. Given administrative processing lags in SSI receipt, applications are the outcome where I expect to see the most immediate effect from the implementation of work requirements. Although the SAMWD data are available every month, I conduct the analyses annually because of the difficulty in establishing the treatment dates every month with precision and because I do not anticipate an significant changes identifiable every month but can identify annually. The effect will take months if not years to develop due to delays in policy implementation, individuals still receiving food assistance for 3 months after the date of the policy change, exemption policies, time spent unsuccessfully looking for work, and time lags in completing the SSI application process, including medically documenting a disability through a healthcare provider. Recipiency faces the internal administrative processing lag as well, along with a potential appeals process. I convert all the SAMWD outcome variables to the rate per 10,000 non-elderly adults using Census population data, to adjust for population size. The final sample includes 408 state-years between 2010 and 2017. ${ }^{11}$ The data on the number of exemptions taken by states under the $15 \%$ exemption rule also come from USDA correspondence with the states, but

11 The District of Columbia is included in the study sample. 
are only available from 2012 through 2017, reducing the total sample from 408 to 306 stateyears for any analyses accounting for the 15\% exemptions. Of the 50 states that have work requirements during the sample period, 32 use exemptions at some point. Exemptions are used in $16 \%$ of state-year observations. On average, states exempt $4 \%$ of ABAWDs rather than the full 15\%. Eleven states in 27 state-years exceeded the 15\% maximum. The maximum number of ABAWDs ever exempted during the sample period was in Washington with 38\% of ABAWDs exempted in 2017.

The SAMWD data are useful because they include the universe of applications and recipiency for SSI, and are the only source of data on applications, the disability claiming margin most likely to be affected by the policy change. However, the SAMWD lacks demographic information and does not include information on food assistance receipts. Therefore, I use the CPS data to create state-level measures of SNAP and SSI receipt overall and among two groups with characteristics likely to affect SSI eligibility, having a disability, or being in a low-income household.

In addition to not including information on applications for SSI, one well-known limitation with the CPS is the under-reporting of disability status and enrollment in public assistance programs. Under-reporting of public assistance receipt, in general, is well-documented (Klerman et al., 2005; Pascale et al., 2009; Meyer et al., 2018; Parker, 2011). Concerning SNAP specifically, as many as 50\% of recipients do not report receipt in the CPS (Meyer et al., 2018; Parker, 2011). Only about $80 \%$ of SSI benefits received are captured by the CPS (Parolin, 2019). However, the CPS does offer the most comprehensive measure of disability available and the ability to create SSI receipt outcomes for subgroups based on disability status and income., i.e., average reported probabilities of SSI enrollment, overall and among individuals reporting a disability or income $<150 \%$ of the FPL.

The CPS data are based on a monthly survey of U.S. households conducted by the U.S. Census Bureau for the Bureau of Labor Statistics (BLS), which includes a six-question sequence regarding any "serious difficulty" with hearing, vision, memory, physical difficulty, mobility limitations, and personal care limitations. At the annual level, the CPS also includes the Annual Economic and Social Supplement (ASEC), which is colloquially referred to as the "March Supplement" for the month it is administered and contains respondent information for the previous calendar year. The March Supplement queries respondents whether they have a health condition or disability that prevents them from working. Neither the monthly question nor the annual question is sufficient on its own, as well documented in the literature. Using the 2010 CPS and focusing on SSI and SSDI recipients, who presumably have a disability so severe that they cannot engage in "substantial gainful activity," Burkhauser et al. (2012) found that only $84.1 \%$ of the population reporting SSI or SSDI receipt report a work limitation while a mere $63.3 \%$ of the population reporting SSI or SSDI receipt answered "yes" to any one of the six-question sequence. Combining the measures improves identification of those with a disability - 92\% of the population reporting SSI or SSDI receipt answered affirmatively to either the work limitation or one of the six-question sequence. I list the six-question sequence and work limitation question in Appendix B. The work limitation question is only measured at the annual level, making analyses for this subgroup only possible at the annual level. 
In generating the analysis sample, I begin by restricting the data to the 1,581,887 respondents surveyed between 2010 through 2017. Restricting the sample to adults between 18 and 49 without children reduces the sample to 297,424. These data are then collapsed at the stateyear level, yielding 408 observations for analysis. Outcomes are aggregated for SNAP and SSI receipt overall and for SNAP and SSI receipt among those reported disabilities or work limitations and among those reporting incomes $<150 \%$ of the FPL. In the underlying sample, $11 \%$ report a work limitation, $15 \%$ report a disability or a work limitation, and $22 \%$ report an income $<150 \%$ of the FPL.

Robustness checks on the main specification include state-level controls from the CPS and other data sets. From the CPS, I calculated the fraction of the population by race/ethnicity (White, Black, Hispanic), by prime working age (ages 25-54), by gender (female or male), and with a high school diploma. Caseloads for AFDC/TANF per 1,000 population, which proxies for the institutional environment concerning public assistance; the unemployment rate; the poverty ratio (proportion of the population below the FPL/total population); and the state minimum wage were obtained from the Kentucky Center for Poverty. ${ }^{12}$ The unemployment rate, the state minimum wage, and the poverty ratio are intended to control general economic conditions. Medicaid expansions have been shown to decrease SSI receipt (Burns and Dague, 2017), so I created variables using data on Medicaid expansions from the Kaiser Foundation. ${ }^{13}$ Because medical cannabis laws may increase applications and receipt of SSI (Maclean et al., 2019), and recreational cannabis laws may increase SSI applications (Maclean et al., 2020), I use data on medical and recreational dispensary access from Powell et al. (2018), the Prescription Drug Abuse Policy System, local news sources, and Procon.org. to create controls for cannabis access. In addition, because Prescription Drug Monitoring Programs have been shown to affect opioid use (Buchmueller and Carey, 2018), which in turn affects labor market outcomes (Harris et al., 2020), I use data on "Must Access" PDMPs from the Prescription Drug Abuse Policy System. ${ }^{14}$ Such laws require prescribers to access the system before issuing a prescription. ${ }^{15}$ Approximately $20 \%$ of the sample state-years occurred after the implementation of "Must Access" PDMP laws, 28\% after entry by legal medical cannabis dispensaries, and $4 \%$ after entry by legal recreational cannabis dispensaries (Table A2 in Appendix shows descriptive statistics for the control variables and the results from tests for differences in the control variables between state-year observations with and without work requirements).

\section{Empirical Strategy}

The following equation shows the linear model estimated by Ordinary Least Squares for the main difference-in-differences analysis.

12 University of Kentucky Center for Poverty Research Data, http://ukcpr.org/resources/national-welfare-data

13 Status of State Action on the Medicaid Expansion Decision. https://www.kff.org/health-reform/state-indicator/stateactivity-around-expanding-medicaid-under-the-affordable-care-act/?currentTimeframe $=0 \&$ sortModel=\%7B $\% 22 \mathrm{colI}$ d\%22:\%22Location\%22,\%22sort\%22:\%22asc\%22\%7D. Accessed 08/03/2020.

14 Prescription Drug Abuse Policy System. Pdaps.org. Accessed 08/03/2020.

15 I use "Must Access" PDMP laws, which the literature has shown drive the effect of PDMPs on opioid prescribing (Buchmueller and Carey, 2018), and cannabis dispensary access, which Powell et al. (2018) showed is necessary for medical cannabis laws to affect opioid use. I assume that recreational cannabis dispensaries similarly have a much larger effect than legalization alone and use recreational cannabis dispensary access rather than just legalization. 


$$
\text { Outcome }_{s t}=\alpha+\gamma^{\star} \text { WorkReqt }_{s t}+\lambda_{s}+\eta_{t}+\varepsilon_{s t}
$$

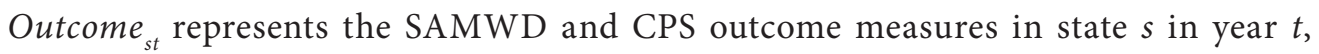
adjusted by population. WorkReqt $t_{s t}$ is an indicator variable for whether state $s$ has SNAPrelated ABAWD work requirements in time $t$. State fixed effects and year fixed effects are given by $\lambda_{s}$ and $\eta_{t}$, respectively. Both SNAP and SSI are sensitive to economic conditions and labor market-related policies, underscoring the importance of controlling for changes over time in general economic conditions and state-specific time-invariant differences in labor market conditions. I supplement the difference-in-differences strategy with event studies to evaluate treatment leads and lags. To implement the event studies, I include the full range of possible treatment leads and lags. For Rhode Island, which implemented work requirements in 2018, I use policy leads based on policy implementation in 2018 Although I do not have the underlying documentation before 2010, CBPP analyses indicate that some states that implemented work requirements in 2010 were already doing them in phases during 2009 (CBPP, 2019b). This issue is explored by estimating groupspecific effects, with groups based on the first year in the data with a work requirement in place. Work requirement implementation occurs in period zero. Note that because Virginia and West Virginia both gain and lose work requirements during this time period, they are not included in the event studies, reducing the total number of observations to 384 state-years.

I assume that the supply side is not changing meaningfully within states during this time period beyond what can be captured by state and year fixed effects and corroborated by including the control variables. (Partly, this reflects an absence of data available on the supply side with a corresponding gap in the literature). Time-varying differences affecting all states and counties will be subsumed in the year fixed effects in the empirical analysis, and time-invariant state-level characteristics will be controlled for with state fixed effects.

Recent work shows difference-in-differences estimates are biased when the timing of treatment varies across units (Borusyak and Jaravel, 2017; Athey and Imbens, 2022; Goodman-Bacon, 2021; de Chaisemartin and d'Haultfoeuille, 2020). To identify the extent of the variation across treatment comparisons, I conduct diagnostics as described in Goodman-Bacon, 2021. Based on these diagnostics, I further explore the robustness of the results, following Callaway and Sant'Anna (2021) in estimating treatment leads and lags by treatment cohort before averaging the leads and lags. Because of issues with time-varying covariates confounding the policy effect, the main analyses include only state and yearfixed effects. I run supplemental regressions controlling for state-level demographics, policies, and economic conditions.

I also conduct additional robustness checks on the treatment variable by weighting the work requirement variable by the size of the likely affected population, using the percentage of ABAWDS reported as living in counties with work requirements, and using the percentage of counties with a work requirement. I also test for any impact from the ability of states to exempt up to $15 \%$ of the ABAWD population by weighting the treatment variable by the percentage of ABAWDs affected, accounting for any exemptions taken. 


\section{Results}

\subsection{Descriptive statistics}

Figures A1-A3 in Appendix show how the raw data have evolved over time and indicate a general decrease in applications and receipt although the decline in applications is steeper than the decline in recipients. These trends run contrary to trends before 2010, with the causes of those earlier increases extensively studied (Autor and Duggan, 2003). This general decrease in disability claims since 2010 was documented in SSA Briefing Paper No. 2019-01 (2019b). The trend appears relatively uniform except in 2015 when the decline appears to temporarily plateau before declining again. SNAP receipt among all groups is generally flat in the first part of the period before trending downward starting around 2015, while overall SSI receipt is fairly flat over time, but the likelihoods of reporting SSI receipt among individuals with self-reported difficulties or who are with lower income trend similarly to the applications and recipients measured using the administrative claims data.

Although work requirements were reinstated over this time period in all states except Rhode Island, they do not appear to be causing an increase in SSI as evident in the raw data. Table A3 in Appendix compares the outcome and control variables for state-years with and without work requirements across the two data sets using means comparisons. Because all but nine states implemented work requirements during the sample period, state-years with work requirements are compared with those without rather than further differentiating between the eight states that began the period with work requirements and Rhode Island, which did not implement a work requirement until 2018. States without work requirements consistently have higher SSI applications and SNAP and SSI recipiency rates.

\subsection{Regression analyses}

Tables 1 shows regression results for applications and recipients of SSI per 10,000 population from the SAMWD and SNAP and SSI recipiency rates from the CPS. The first panel of the table

Table 1 Regression results - overall effects

\begin{tabular}{lcccc}
\hline & $\mathbf{( 1 )}$ & $\mathbf{( 2 )}$ & $\mathbf{( 3 )}$ & $\mathbf{( 4 )}$ \\
\cline { 2 - 5 } & $\begin{array}{c}\mathbf{S S I} \\
\text { applications } \\
\text { per 10K }\end{array}$ & $\begin{array}{c}\text { SSI } \\
\text { recipients } \\
\text { per 10K }\end{array}$ & SNAP rate & SSI rate \\
\hline Panel A: Main Results & -0.002 & 0.333 & -0.000 & -0.004 \\
Any work requirement & $(0.510)$ & $(0.241)$ & $(0.001)$ & $(0.003)$ \\
Observations & 408 & 408 & 408 & 408 \\
Within $R$-squared & 0.625 & 0.426 & 0.068 & 0.234 \\
Standard $R$-squared & 0.967 & 0.915 & 0.852 & 0.743 \\
Mean & 33.43 & 11.19 & 0.13 & 0.02 \\
\% Change from mean & $0.0 \%$ & $3.0 \%$ & $0.0 \%$ & $-20.0 \%$ \\
Partial Eta-squared & 0.000 & 0.007 & 0.008 & 0.000 \\
90\% Conf. interval & $0-0.019$ & $0-0.028$ & $0-0.030$ & $0-0.006$ \\
\hline
\end{tabular}


Table 1 Continued

\begin{tabular}{lcccc}
\hline & $\mathbf{( 1 )}$ & $\mathbf{( 2 )}$ & $\mathbf{( 3 )}$ & $\mathbf{( 4 )}$ \\
\cline { 2 - 5 } & $\begin{array}{c}\text { SSI } \\
\text { applications } \\
\text { per 10K }\end{array}$ & $\begin{array}{c}\text { SSI } \\
\text { recipients } \\
\text { per 10K }\end{array}$ & SNAP rate & SSI rate \\
\hline Panel B: Including State-Level Controls & & & \\
Any work requirement & -0.201 & 0.173 & 0.000 & -0.002 \\
Observations & $(0.500)$ & $(0.185)$ & $(0.001)$ & $(0.003)$ \\
Within R-squared & 400 & 400 & 400 & 400 \\
Standard R-squared & 0.700 & 0.552 & 0.110 & 0.329 \\
\% Change from mean & 0.974 & 0.938 & 0.858 & 0.774 \\
Partial Eta-squared & $-0.6 \%$ & $1.5 \%$ & $0.0 \%$ & $-10.0 \%$ \\
90\% Conf. interval & 0.001 & 0.004 & 0.003 & 0.000 \\
\hline
\end{tabular}

Notes: Underlying data come from the SAMWD and CPS (2010-2017). Each column within each panel represents a separate regression. Outcomes in Columns 1 and 2 are measured per 10,000 population; Outcomes in Columns 3 and 4 are rates. All regressions include state and year fixed effects. In Panel B, state-level controls are added, including TANF caseload, unemployment rate, state minimum wage, poverty ratio, high school completion rates, Medicaid expansions, fractions of the population that are White, Black, Hispanic, of prime age, and female; Governor's political party affiliation, "Must Access" PDMP, medical cannabis dispensary access, and recreational cannabis dispensary access. The first panel includes 408 state-years, while the lower panel includes 400 state-years because the District of Columbia does not have a Governor. Standard errors are clustered at the state level and reported in parentheses.

${ }^{\star \star \star} p<0.01,{ }^{\star \star} p<0.05,{ }^{\star} p<0.1$.

includes only year and state fixed effects, while the lower panel includes the state-level controls. No statistically significant effects exist from work requirements on SSI applications and recipients from the administrative claims data or on the rates of SNAP and SSI recipiency from the CPS. The magnitudes of the coefficients are generally also quite small relative to the means of the outcome variables. The partial eta-squared values suggest that the Any Work Requirement variable has little explanatory power.

Table 2 follows the same structure as Table 1 and shows that even among those more likely to be eligible for SNAP and SSI, the effect of work requirements is not statistically significant, and this lack of significance changes little with the inclusion of a large number of state-level controls. As in Table 1, the magnitudes of the coefficients are generally small relative to the mean and the partial eta-squared values suggest that work requirements do little to explain changes in SNAP and SSI rates among those with self-reported disabilities or low income.

Following Goodman-Bacon (2021) in decomposing the results, Figure 2 shows substantial heterogeneity exists depending on the group comparisons. In particular, in both Panel A and $B$, the most positive effects come from comparing the group treated earlier with the later treated group acting as a control, while other comparisons indicate negative or zero effects. The differences in weighting also are substantial. 
Table 2 Regression results - rates among those with self-reported disabilities or low income

\begin{tabular}{lcccc}
\hline & $\mathbf{( 1 )}$ & $\mathbf{( 2 )}$ & $\mathbf{( 3 )}$ & $\mathbf{( 4 )}$ \\
\cline { 2 - 5 } & $\begin{array}{c}\text { SNAP } \\
\text { rate - difficulty }\end{array}$ & $\begin{array}{c}\text { SNAP } \\
\text { rate - low } \\
\text { income }\end{array}$ & $\begin{array}{c}\text { SSI } \\
\text { rate - difficulty }\end{array}$ & $\begin{array}{c}\text { SSI } \\
\text { rate - low } \\
\text { income }\end{array}$ \\
\hline Panel A: Main Results & & & & \\
Any work requirement & -0.001 & 0.004 & -0.013 & -0.007 \\
Observations & $(0.008)$ & $(0.004)$ & $(0.011)$ & $(0.011)$ \\
Within $R$-squared & 408 & 408 & 408 & 408 \\
Standard $R$-squared & 0.072 & 0.018 & 0.102 & 0.106 \\
Mean & 0.372 & 0.518 & 0.489 & 0.569 \\
\% Change from mean & 0.29 & 0.32 & 0.22 & 0.06 \\
Partial Eta-squared & $-0.3 \%$ & $1.3 \%$ & $-5.9 \%$ & $-11.7 \%$ \\
90\% Conf. interval & 0.003 & 0.001 & 0.000 & 0.002 \\
\hline Panel B: Including State-Level Controls & 0.014 & $0-0.004$ & $0-0.017$ \\
Any work requirement & 0.002 & 0.005 & -0.007 & -0.002 \\
Observations & $(0.008)$ & $(0.004)$ & $(0.012)$ & $(0.010)$ \\
Within $R$-squared & 400 & 400 & 400 & 400 \\
Standard $R$-squared & 0.124 & 0.067 & 0.167 & 0.179 \\
\% Change from mean & 0.410 & 0.542 & 0.526 & 0.606 \\
Partial Eta-squared & $0.7 \%$ & $1.6 \%$ & $-3.2 \%$ & $-3.3 \%$ \\
90\% Conf. interval & 0.001 & 0.000 & 0.000 & 0.003 \\
\hline Notes: Underlying & $0-0.013$ & $0-0.007$ & $0-0.007$ & $0-0.022$ \\
\hline
\end{tabular}

Notes: Underlying data come from the SAMWD and CPS (2010-2017). Each column in each panel represents a separate regression. Difficulty refers to those with self-reported disabilities and Low Income refers to self-reported income $<150 \%$ of the FPL. All regressions include state and year fixed effects. In Panel B, state-level controls are added, including TANF caseload, unemployment rate, state minimum wage, poverty ratio, high school completion rates, Medicaid expansions, fractions of the population that are White, Black, Hispanic, of prime age, and female; Governor's political party affiliation, "Must Access" PDMP, medical cannabis dispensary access, and recreational cannabis dispensary access. The first panel includes 408 state-years, while the lower panel includes 400 state-years because the District of Columbia does not have a Governor. Standard errors are clustered at the state level and reported in parentheses.

${ }^{\star \star \star} p<0.01,{ }^{\star \star} p<0.05,{ }^{\star} p<0.1$.

To correct for these obvious issues and to evaluate the possibility that policy effects may differ over time and across treated units, I proceed with the event studies. Traditional event studies regressing outcomes on a series of policy leads and lags are included in Figures A4 and A5 in Appendix. Given the issues identified in the decomposition in Figure 2, the unadjusted event studies suffer from a variety of biases, driven by differences in the number of units across treated groups and differences in the timing of treatment. Therefore, for my main event study approach, I follow recent work by Callaway and Sant'Anna (2021), through which I estimate separate event studies for groups of states, defined by the year the work requirement was implemented, with leads and lags averaged for each group and weighted by the number of states in 
Figure 2 Decomposition of DID results. Panel A: Decomposition of overall results. Panel B: Decomposition of results for those with self-reported disabilities or low income.

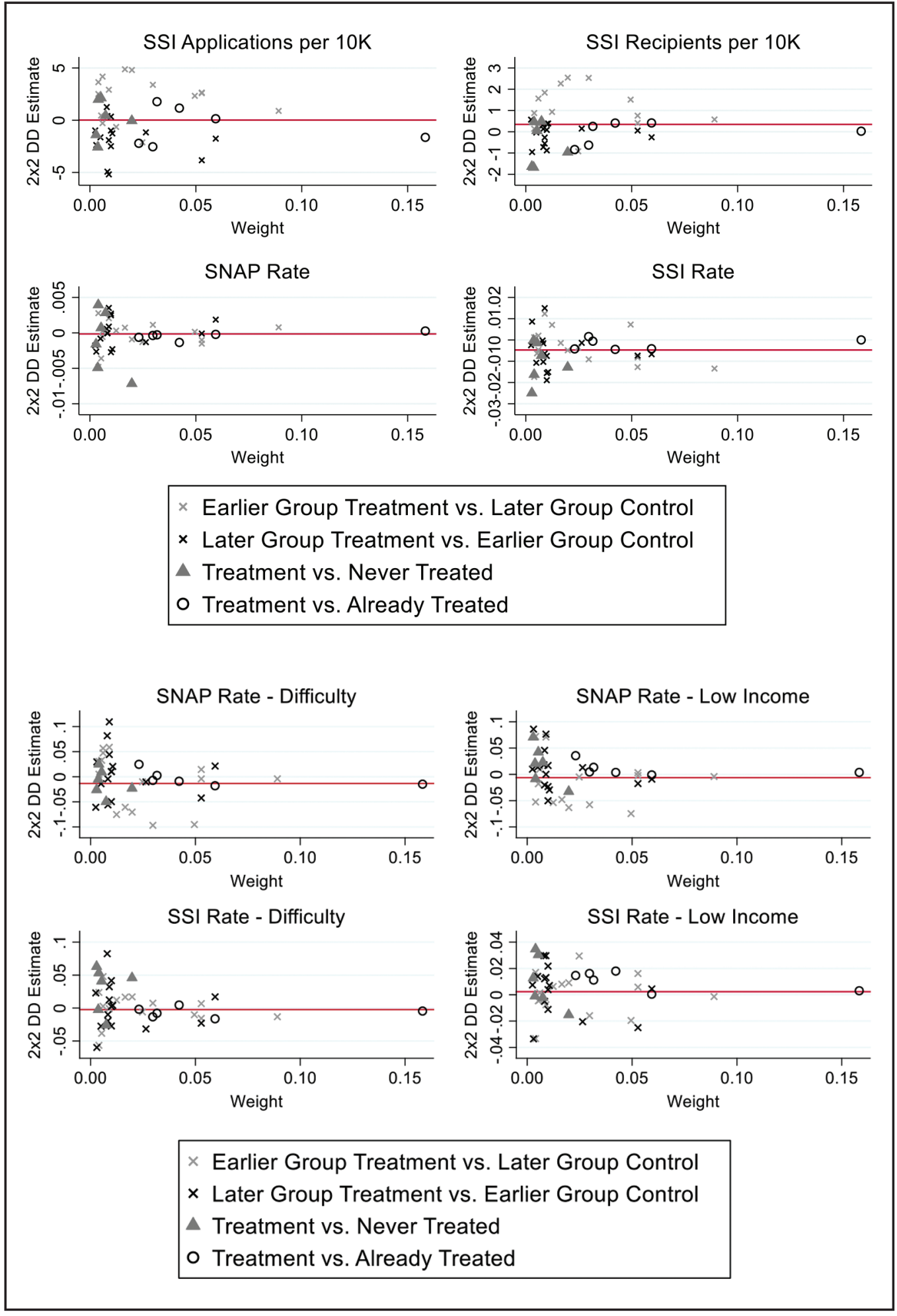

Notes: Decomposition based on Goodman-Bacon (2021).

each group to calculate overall effects by period. (Table A4 in Appendix shows the averaged coefficients by period (year) relative to when the work requirement was implemented).

The event studies shown in Figures 3 and 4 show little evidence of pretrends, decreasing concerns about policy endogeneity. Figure 3 shows a lagged effect on SSI applications, but 
Figure 3 Event studies - Overall effects.

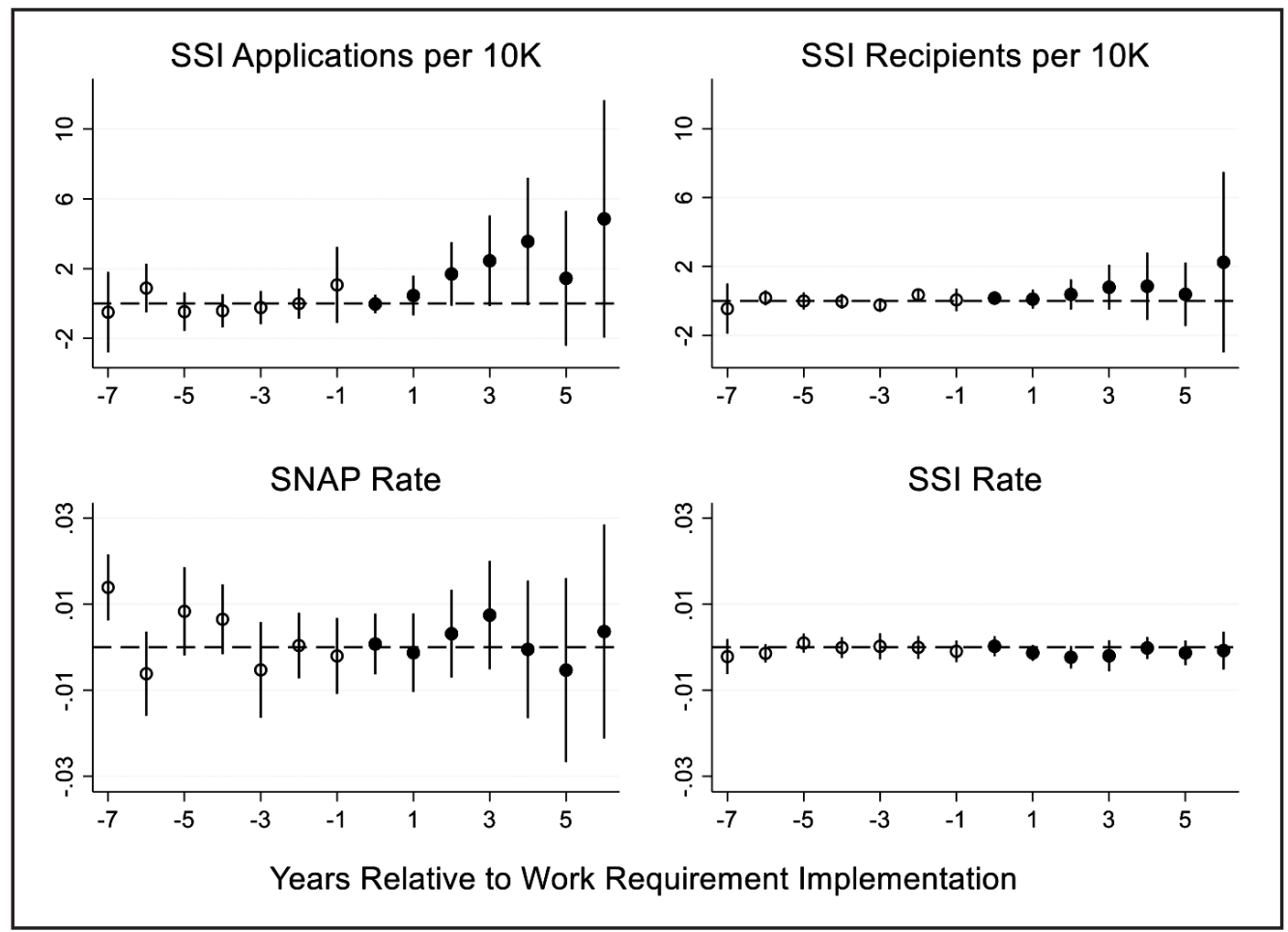

Notes: Average Treatment Effects on the Treated (ATT) are graphed by year relative to work requirement implementation. ATTs are calculated by running event studies separately for each group as defined by year of work requirement implementation. Leads and lags are then averaged, weighting by the share of states in each group. Virginia and West Virginia gained and reversed work requirements during the sample period and are omitted from the event study analysis. Outcomes are measured per 10,000 population in the first two graphs and are rates in the second two graphs. Underlying regressions control for state and year fixed effects with standard errors clustered at the state level.

little overall effect on SNAP receipt or SSI receipt, whether the latter is measured using the administrative or the survey data. Figure 4 suggests that effects may be concentrated among those with self-reported disabilities, who report a drop in SNAP receipt with the implementation of the work requirement followed by a weaker lagged effect on SSI receipt. Table A4 in Appendix reports the period-level coefficients. Relative to the mean values, the coefficients indicate marginally significant, period-specific increases in SSI applications ranging from $5 \%$ in year 2 to $10.6 \%$ in year 4 . For SNAP receipt, no overall effects are statistically significant, but among those with self-reported disabilities, a marginally significant decrease of $15 \%$ in year 1 is followed by a statistically significant decrease of $24 \%$ in year 2 . The decreases in SNAP receipt may explain the marginally significant 23\% decrease in SSI receipt in year 5 among those with self-reported disabilities. For lower income individuals, a marginally significant decrease of $12 \%$ in SNAP receipt appears to exist with no corresponding effect on SSI receipt. Figures A6 and A7 in Appendix show the results by group, confirming that the earlier adopters of work requirements are driving the increase in applications, in line with the documented lagged effect. The group-specific effects for the other outcomes are less clear with general reductions in SNAP receipt and SSI receipt. The results for the two subgroups indicate heterogeneity across groups with negative effects on SNAP recipiency for cohorts of states implementing work requirements in the middle of the sample period. Effects by 
Figure 4 Event studies for SSA recipients.

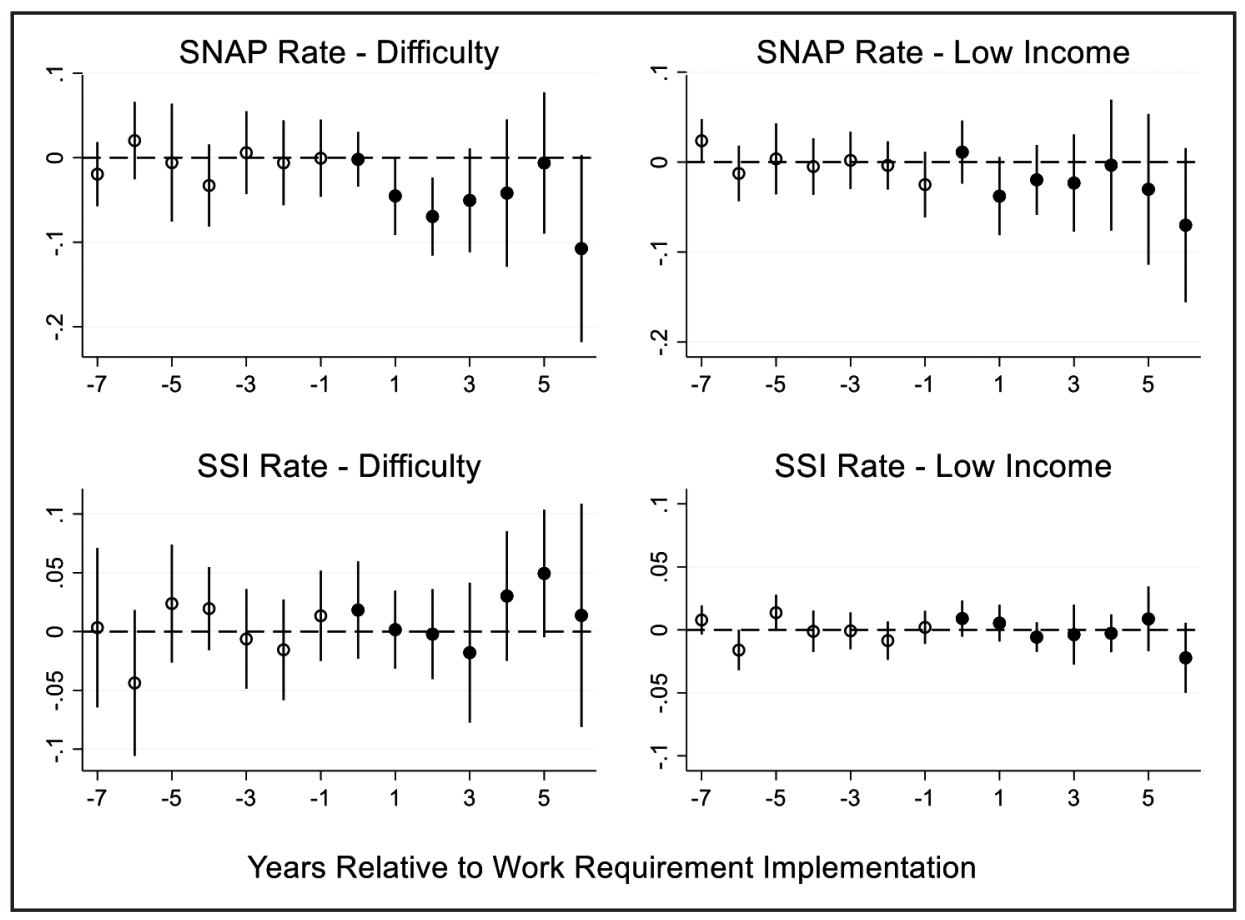

Notes: Average Treatment Effects on the Treated (ATT) are graphed by year relative to work requirement implementation. ATTs are calculated by running event studies separately for each group as defined by year of work requirement implementation. Leads and lags are then averaged, weighting by the share of states in each group. Virginia and West Virginia gained and reversed work requirements during the sample period and are omitted from the event study analysis. Underlying regressions control for state and year fixed effects with standard errors clustered at the state level.

subgroup for SSI receipt do not show a clear pattern and are generally insignificant at the group level.

Table 3 presents an averaged summary of the treatment effect from the Callaway and Sant'Anna (2021) estimates, paralleling the difference-in-differences estimates in Tables 1 and 2. As in Figures 3 and 4, and in contrast to the biased results in Tables 1 and 2, the estimates in Table 3 suggest the possibility of an increase in SSI applications overall and a decrease in SNAP recipiency among those with self-reported disabilities. The implementation of work requirements is associated with a marginally significant $4 \%$ increase in the number of applications per 10,000 population, and a marginally significant decrease of $12.8 \%$ in SNAP receipt among those with self-reported disabilities. The magnitudes of the (highly) insignificant coefficients in Table 3 are generally small (5\% or less of the mean).

As a final robustness check or extension of the main analysis, I evaluate whether the results in Table 1 vary meaningfully with the size of the affected population with results reported in Tables A5 and A6 in Appendix. The coefficients remain insignificant as in the main results in Table 1, except for the rate of SNAP recipiency on which any work requirement has no statistically significant effect. When weighted by the number of counties affected the coefficient for the treatment variable becomes negative and marginally statistically significant. When weighted by the number of ABAWDs affected the coefficient on the work requirement variable becomes statistically significant at the 0.05 level. The coefficient becomes larger when the work requirement measure is further adjusted by the number of exemptions taken. 
Table 3 Average treatment effects from Callaway and Sant'Anna (2021) analysis

\begin{tabular}{|c|c|c|c|c|}
\hline & (1) & (2) & (3) & (4) \\
\hline & $\begin{array}{c}\text { SSI } \\
\text { applications } \\
\text { per 10K }\end{array}$ & $\begin{array}{c}\text { SSI } \\
\text { recipients } \\
\text { per 10K }\end{array}$ & SNAP rate & SSI rate \\
\hline \multirow[t]{2}{*}{ Any work requirement } & $1.339^{\star}$ & 0.460 & 0.001 & -0.001 \\
\hline & $(0.806)$ & -0.499 & -0.004 & $(0.001)$ \\
\hline Mean & 33.43 & 11.19 & 0.13 & 0.02 \\
\hline \multirow[t]{2}{*}{$\%$ Change from mean } & $4.0 \%$ & $4.1 \%$ & $0.8 \%$ & $5.0 \%$ \\
\hline & $\begin{array}{c}\text { SNAP } \\
\text { Rate- Difficulty }\end{array}$ & $\begin{array}{c}\text { SNAP } \\
\text { Rate - Low } \\
\text { Income }\end{array}$ & $\begin{array}{c}\text { SSI } \\
\text { Rate- Difficulty }\end{array}$ & $\begin{array}{c}\text { SSI } \\
\text { Rate - Low } \\
\text { Income }\end{array}$ \\
\hline \multirow[t]{2}{*}{ Any work requirement } & $-0.037^{\star}$ & -0.016 & 0.010 & 0.001 \\
\hline & $(0.019)$ & $(0.018)$ & $(0.018)$ & $(0.006)$ \\
\hline Mean & 0.29 & 0.32 & 0.22 & 0.06 \\
\hline$\%$ Change from mean & $12.8 \%$ & $5.0 \%$ & $4.5 \%$ & $1.7 \%$ \\
\hline Observations & 384 & 384 & 384 & 384 \\
\hline
\end{tabular}

Notes: Average Treatment Effects on the Treated (ATT) are calculated by running event studies separately for each group as defined by year of work requirement implementation. Leads and lags are then averaged, weighting by the share of states in each group. Virginia and West Virginia gained and reversed work requirements during the sample period and are omitted from the event study analysis. Underlying regressions control for state and year fixed effects with standard errors clustered at the state level.

\section{Discussion}

Using administrative claims data, this study found suggestive evidence of a relatively small, lagged increase in SSI applications, following the implementation of SNAP-related work requirements. Survey data indicate no overall changes in the rates of SNAP or SSI recipiency following the implementation of work requirements, but among those with self-reported disabilities, SNAP receipt appears to drop substantially following the implementation of work requirements, potentially leading to a delayed increase on SSI receipt in subsequent years. Lower income individuals may also experience a reduction in SNAP receipt, but no corresponding effect on SSI receipt was found in this study. Evidence using continuous treatment measures indicates that the effect on SNAP receipt may vary with the size of the population affected.

Although it appears that most applications induced by food assistance-related work requirements are not successful, given no corresponding increase in overall recipiency, it appears that among those with self-reported disabilities, substitution across welfare programs may exist with potentially severe consequences for those affected. Among young adults receiving SSI, future employment probabilities are substantially reduced (Deshpande, 2016). Even among those on SSDI, which requires some workforce attachment, at least historically, future employment likelihood is significantly reduced (Bound, 1989; Maestas et al., 2013; French and Song, 2014; von Wachter et al., 2011). These effects are likely greater for SSI. Previous work documents the total expected time on SSI pre-retirement to be 10.5 years, including multiple spells, with the average spell for adults only eligible for SSI estimated to be 6.4 years, and for those receiving SSI and SSDI, 1.3 years (Rupp and Scott, 1995). Receiving SSI may also increase 
eligibility for housing assistance, further raising the cost of ever leaving SSI once enrolled (Hembre et al., 2019).

My inability to measure lagged effects for the majority (28) of states that implemented work requirements in 2016 and 2017 limits the conclusions of this paper. It may be that the sample period was too short to detect an effect in those states or I may not be fully capturing the relative attractiveness of staying in SNAP and working versus switching to SSI in the context of the growing economy that existed during the sample period, even after controlling for a variety of state-specific characteristics. In addition, Deshpande and Li (2019) document changes during this time period in supply-side constraints with likely increased search costs due to office closings, particularly for those with moderately severe conditions. The office closings they report, based on confidential data, were common during the sample period and are found to be associated with reduced SSI claiming. Such an effect could be negating the effect of the work requirements if office closings are correlated with the implementation of work requirements. Across states, it is also almost impossible to verify how work requirements are operationalized. Some states administer the work requirements themselves, while an unknown number outsource the enforcement of work requirements to private vendors. The market in which these private vendors operate is opaque and the popular press reports that exist suggest that applicants and participants do not benefit from private outsourcing (Brown, 2019; McMillan, 2019).

\section{Conclusion}

In conclusion, this study suggests that policies designed to incentivize employment through work requirements have limited direct effects and cause few spillovers to SSI. However, potentially negative direct effects with possible associated spillovers to SSI may exist among those with self-reported disabilities, a particularly vulnerable population.

These results have implications for existing work requirement programs in TANF, housing assistance, and particularly Medicaid, where work requirements have been heavily litigated. They also suggest the state and federal governments might consider using caution moving forward with the increased work requirements that they currently have placed on hold. Those negatively impacted by work requirements seem likely to be among the most vulnerable members of society. Policymakers might consider weighing the costs to this population against the limited documented benefits of work requirements, which at best appear to only marginally increase employment (Brantley et al., 2020; Harris, 2020; Wasif and Stith, 2020). In addition, while some cost savings may be realized through individuals dropping out of SNAP (Harris, 2020; Brantley et al., 2020), any substitution across programs indicates potential cost increases to public spending - SNAP benefits alone cost much less than SSI benefits and SNAP application costs are lower for both recipients and the government. Costs associated with the implementation and administration of work requirements also may not be negligible. Estimates of state-level costs of implementing Medicaid-related work requirements range from $\$ 10$ million in New Hampshire to $\$ 250$ million in Kentucky (GAO, 2019).

The findings in this study document what appear to be limited demand-side responses to work requirements overall with a stronger response among a population on the margin 
between participating in SNAP alone or opting into a disability program. How important supply-side factors are overall and relative to demand-side responses remains an ongoing question with respect to public assistance more generally and one that must be answered before the causal mechanisms behind the effects of work requirements on disability claiming can be fully understood.

\section{Declarations}

\section{Availability of data}

Data used in this study are publicly available. All data were obtained from publicly available data sources except for the USDA correspondence received from Dr. Timothy Harris.

\begin{tabular}{|c|c|}
\hline Data & URL \\
\hline USDA correspondence & Timothy Harris, Illinois State University. fharr1@ilstu.edu \\
\hline $\begin{array}{l}\text { SSA State Agency Monthly } \\
\text { Workload Data }\end{array}$ & https://www.ssa.gov/disability/data/ssa-sa-mowl.htm \\
\hline Current Population Survey & www.ipums.org \\
\hline $\begin{array}{l}\text { University of Kentucky } \\
\text { Center for Poverty } \\
\text { Research Data }\end{array}$ & http://ukcpr.org/resources/national-welfare-data \\
\hline Medicaid Expansion & $\begin{array}{l}\text { https://www.kff.org/health-reform/state-indicator/state- } \\
\text { activity-around-expanding-medicaid-under-the-affordable- } \\
\text { care-act/?currentTimeframe=0\&sortModel=\%7B\%22colld\% } \\
\text { 22:\%22Location\%22,\%22sort\%22:\%22asc\%22\%7D. }\end{array}$ \\
\hline $\begin{array}{l}\text { Prescription Drug } \\
\text { Monitoring Programs }\end{array}$ & www.pdaps.org \\
\hline \multirow[t]{3}{*}{$\begin{array}{l}\text { Medical and recreational } \\
\text { cannabis access }\end{array}$} & $\begin{array}{l}\text { Powell, David; Rosalie Liccardo Pacula; Mireille Jacobson } \\
\text { (2018). Do Medical Marijuana Laws Reduce Addictions and } \\
\text { Deaths Related to Pain Killers? Journal of Health Economics, } \\
\text { 58:29-42 }\end{array}$ \\
\hline & www.pdaps.org \\
\hline & www.procon.org \\
\hline
\end{tabular}

\section{Code availability}

Stata code used to clean and analyze the data is available upon request.

\section{Conflicts of interest/competing interests}

The author has no conflicts of interest to disclose that are relevant to the content of this article.

\section{Funding}

The underlying research for this study was funded by a Social Security Administration-funded grant received through the University of Wisconsin Retirement and Disability Research Consortium. Required disclaimer: "The research reported herein was derived in whole or in part from research activities performed pursuant to a grant from the U.S. Social Security Administration (SSA) funded as part of the Retirement and Disability Research Consortium. The opinions and conclusions expressed are solely those of the author(s) and do not represent the opinions or policy of SSA or any agency of the Federal Government. Neither the United States Government nor any agency thereof, nor any of their employees, makes any warranty, express or implied, or assumes any legal liability or responsibility for the accuracy, completeness, or usefulness of the contents of this report. Reference herein to any specific commercial product, process or service by trade name, trademark, manufacturer, or otherwise does not necessarily constitute or imply endorsement, recommendation or favoring by the United States Government or any agency thereof."

\section{Authors' contributions}

The paper is solo-authored. 


\section{Acknowledgements}

I thank Richard Santos, Jeffrey Smith, Michael Collins, Mary Hamman, Hallie Leinhardt, and Matt Messel for crucial feedback. I also would like to thank Timothy Harris for sharing the data from the United States Department of Agriculture on county-level work requirements, Judy Bartfeld for her institutional knowledge, seminar participants at the University of Wisconsin Center for Financial Security's Household Finance Seminar Series for helpful comments, and Usamah Wasif, Avinandan Chakraborty, and Samsun Naher for excellent research assistance.

\section{References}

Athey, Susan; Guido Imbens (2022): Design-Based Analysis in Difference-In-Differences Settings with Staggered Adoption. Journal of Econometrics 226(1), 62-79.

Autor, David H.; Mark G. Duggan (2003): "The Rise in the Disability Rolls and the Decline in Unemployment." The Quarterly Journal of Economics 118(1), 157-206.

Baicker, Katherine; Amy Finkelstein; Jae Song; S. Sarah Taubman (2014): The Impact of Medicaid on Labor Market Activity and Program Participation: Evidence from the Oregon Health Insurance Experiment. American Economic Review 104(5): 322-328.

Besley, Timothy; Stephen Coate (1992): Workfare Versus Welfare: Incentive Arguments for Work Requirements in Poverty-Alleviation Programs. American Economic Review 82(March), 249-262.

Black, Dan; Kermit Daniel; Seth Sanders (2002): The Impact of Economic Conditions on Participation in Disability Programs: Evidence from the Coal Boom and Bust. American Economic Review 92(1), 27-50.

Borusyak, Kirill; Xavier Jaravel (2017): Revisiting Event Study Designs. SSRN Working Paper No. 2826228.

Bound, John (1989): The Health and Earnings of Rejected Disability Insurance Applicants. American Economic Review 79(3), 482-503.

Brantley, Erin; Drishti Pillai; Leighton Ku (2020): Association of Work Requirements with Supplemental Nutrition Assistance Program Participation by Race/Ethnicity and Disability Status, 2013-2017. JAMA Network Open 3(6), e205824.

Brown, H. C. (2019): When the Government Mandates Work Requirements for Food Stamps, Who Actually Profits? The Counter. https://thecounter.org/work-requirements-snap-mandatory-employment-training-program-profits/. Accessed on January 01, 2022.

Buchmueller, Thomas C.; Colleen Carey (2018): The Effect of Prescription Drug Monitoring Programs on Opioid Utilization in Medicare. American Economic Journal: Economic Policy 10(1), 77-112.

Burkhauser, Richard; Andrew Houtenville; Jennifer Tennant (2012): Capturing the Elusive Working-Age Population With Disabilities: Reconciling Conflicting Social Success Estimates from the Current Population Survey and American Community Survey. Journal of Disability Policy Studies 24(4), 195-205.

Burns, M.; L. Dague (2017): The Effect of Expanding Medicaid Eligibility on Supplemental Security Income Program Participation. Journal of Public Economics 149, 20-34.

Callaway, Brantley; Pedro H.C. Sant'Anna (2021): Difference-in-Differences with Multiple Time Periods. Journal of Econometrics 225(2), 200-230.

Center for Budget and Policy Priorities (CBPP) (2019a): Chart Book: SNAP Helps Struggling Families Put Food on the Table. November 7, 2019. https://www.cbpp.org/research/food-assistance/chart-book-snaphelps-struggling-families-put-food-on-the-table. Accessed on January 28, 2022.

Center for Budget and Policy Priorities (CBPP) (2019b): States Have Requested Waivers from SNAP's Time Limit in High Unemployment Areas for the Past Two Decades. December 5, 2019. https://www.cbpp.org/ research/food-assistance/states-have-requested-waivers-from-snaps-time-limit-in-high-unemployment. Accessed on January 28, 2022.

Charles, Kerwin Kofi; Yiming Li; Melvin Stephens Jr. (2018): Disability Benefit Take-Up and Local Labor Market Conditions. Review of Economics and Statistics 100(3), 416-423.

Coe, N. B.; April Yanyuan Wu (2014): What Impact Does Social Security Have on the Use of Public Assistance Programs Among the Elderly? Working Paper, Center for Retirement Research at Boston College, No. 2014-5.

De Chaisemartin, Clement; Xavier D'Haultfoeuille (2020): Two-Way Fixed Effects Estimators with Heterogeneous Treatment Effects. The Review of Economic Studies 85(2), 999-1028.

Deshpande, Manasi (2016): Does Welfare Inhibit Success? The Long-Term Effects of Removing Low-Income Youth from the Disability Rolls. American Economic Review 106(11), 3300-3330.

Deshpande, Manasi; Yue Li (2019): Who Is Screened Out? Applications Costs and the Targeting of Disability Programs. American Economic Journal: Economic Policy 11(4), 213-248.

Fadulu, Lola (2020): Trump Backs Off Tougher Food Stamp Work Rules for Now. New York Times.

French, Eric; Jae Song (2014): The Effect of Disability Insurance Receipt on Labor Supply. American Economic Journal: Economic Policy 6(2), 291-337. 
Ganong, Peter; Jeffrey B. Liebman (2018): The Decline, Rebound, and Further Rise in SNAP Enrollment: Disentangling Business Cycle Fluctuations and Policy Changes. American Economic Journal: Economic Policy 10(4), 153-176.

Garrett, Bowen; Sherry Glied (2000): Does State AFDC Generosity Affect Child SSI Participation? Journal of Policy Analysis and Management 19(2), 275-295.

Goodman-Bacon, A. (2021): Difference-In-Differences with Variation in Treatment Timing. Journal of Econometrics 225(2), 254-277.

Gray, Colin; Adam Lieve; Elena Prager; Kelsey Pukelis; Mary Zaki (2021): Employed in a SNAP? The Impact of Work Requirements on Program Participation and Labor Supply. NBER Working Paper, No. 28877.

Harris, Matthew; Lawrence M. Kessler; Matthew N. Murray; M. Elizabeth Glenn (2020): Prescription Opioids and Labor Market Pains: The Effect of Schedule II Opioids on Labor Force Participation and Unemployment. The Journal of Human Resources 55(4),1319-1364.

Harris, Timothy (2020): Do SNAP Work Requirements Work? Economic Inquiry 59(1), 72-94.

Hembre, Eric; Carly Urban; Lucie Schmidt (2019): Housing Assistance and SSI Participation. Social Security Administration Working Paper.

Klerman, Jacob Alex; Jeanne S. Ringel; Beth Roth (2005): Under-reporting of Medicaid and welfare in the Current Population Survey. RAND Working Paper. https://www.rand.org/pubs/working_papers/WR169-3. html.

Maclean, Johanna Catherine; Keshar M. Ghimire; Lauren Hersch Nicholas (2019): Medical Marijuana Laws and Disability Applications, Receipts, and Terminations. National Bureau of Economic Research Working Paper No. 23862.

Maclean, Johanna Catherine; Keshare M. Ghimire; Lauren Hersh Nicholas (2020): Marijuana Legalization and Disability Claiming. Health Economics 30, 453-469.

Maestas, Nicole; Kathleen J. Mullen; Alexander Strand (2013): Does Disability Insurance Receipt Discourage Work? Using Examiner Assignment to Estimate Causal Effects of SSDI Receipt. American Economic Review 103(5), 1797-829.

McMillan, Tracie (2019): How One Company Is Making Millions Off Trump's War on the Poor. Mother Jones, January/February Issue.

Meyer, Bruce D.; Nikolas Mittag; Robert M. Goerge (2020): Errors in Survey Reporting and Imputation and their Effects on Estimates of Food Stamp Program Participation. The Journal of Human Resources 57(1), in press.

Parker, Julie (2011): SNAP Misreporting on the CPS: Does It Affect Poverty Estimates. Social, Economic, and Housing Statistics Division Working Paper, 2012-1.

Parolin, Zachary (2019): The Effect of Benefit Underreporting on Estimates of Poverty in the United States. Social Indicators Research 144, 869-898.

Pascale, Joanne; Marc I. Roemer; Dean Michael Resnick (2009): Medicaid Underreporting in the CPS: Results from a Record Check Study. Public Opinion Quarterly 73(3), 497-520.

Powell, David; Rosalie Liccardo Pacula; Mireille Jacobson (2018): Do Medical Marijuana Laws Reduce Addictions and Deaths Related to Pain Killers? Journal of Health Economics 58, $29-42$.

Rozema, Kyle; Nicholas R. Ziebarth (2017): Taxing Consumption and the Take-Up of Public Assistance: The Case of Cigarette Taxes and Food Stamps. Journal of Law and Economics 60(1), 1-27.

Rupp, Kalman; Charles G. Scott (1995): Length of Stay on the Supplemental Security Income Disability Program. Social Security Bulletin 58(1), 29-47.

Schmidt, Lucie (2012): The Supplemental Security Income Program and Welfare Reform. Federal Reserve Board of Boston Public Policy Discussion Paper, 12-3.

Schmidt, Lucie; Purvi Sevak (2004): AFDC, SSI, and Welfare Reform Aggressiveness Caseload Reductions versus Caseload Shifting. Journal of Human Resources 39(3), 792-812.

Social Security Administration (2019a): Annual Report of the Supplemental Security Income Program. May 30, 2019. https://www.ssa.gov/OACT/ssir/SSI19/ssi2019.pdf.

Social Security Administration (2019b): Trends in Social Security Disability Insurance. SSA Briefing Paper No. 2019-01. August 2019. https://www.ssa.gov/policy/docs/briefing-papers/bp2019-01.html

Social Security Administration (2020a): If You're Blind Or Have Low Vision - How We Can Help. Social Security Administration Publication No. 05-10052, January 2020. https://www.ssa.gov/policy/docs/briefing-papers/bp2019-01.html

Social Security Administration (2020b): SSI Annual Statistical Report, 2020. https://www.ssa.gov/policy/ docs/statcomps/ssi_asr/2020/sect10.html. Accessed January 28, 2022. 
Supplemental Nutrition Assistance Program (SNAP) (2015): A Guide on Serving Able-Bodied Adults without Dependents (ABAWDs). United States Department of Agriculture. https://www.fns.usda.gov/snap/ guide-serving-abawds-time-limit-participation. Accessed 9th July 2020.

Thomas, Snyder; Rinkevich Senayt; Yuan Weici (2019): Do Minimum Wages Affect SNAP Benefits? The B.E. Journal of Economic Analysis \& Policy 19(2), 1-6.

United States Government Accountability Office (GAO) (2019): Medicaid Demonstrations: Actions Needed to Address Weaknesses in Oversight of Costs to Administer Work Requirements. Report to Congressional Requesters, October 2019. GAO-20-149.

Vachon, Mallory (2015): Local Labor Market Conditions and the Federal Disability Insurance Program: New Evidence from the Bakken Oil Boom. Available at SSRN 2727381.

von Wachter, Till; Jae Song; Joyce Manchester (2011): Trends in Employment and Earnings of Allowed and Rejected Applicants to the Social Security Disability Insurance Program. American Economic Review 101(7), 3308-3329.

Wasif, U.; S.S. Stith (2020): Food Stamp Program Work Requirements: A Case of Effective Policy or Negative Unintended Consequences? Working Paper. 


\section{Appendix A}

Table A1 State and year information on work requirements

\begin{tabular}{ll}
\hline Work requirements added by year \\
\hline Pre-2010 & Colorado, Delaware, Nebraska, New York, North Dakota, South Dakota, \\
& Texas, West Virginia \\
2011 & None \\
2012 & New Hampshire, Utah, Vermont, Wyoming \\
2013 & lowa, Kansas, Minnesota, Ohio, Oklahoma, Virginia \\
2014 & Hawaii, Maine, Montana, Wisconsin \\
2015 & Indiana, Louisiana, Washington \\
2016 & Alabama, Alaska, Arkansas, Arizona, Connecticut, Florida, Georgia, Idaho, \\
& Kentucky, Maryland, Mississippi, Massachusetts, Missouri, New Jersey, New \\
& Mexico, North Carolina, Oregon, Pennsylvania, South Carolina, Tennessee, \\
2017 & Virginia, West Virginia \\
\hline Work requirements reversed by year \\
\hline 2012 & West Virginia \\
2014 & Virginia \\
\hline
\end{tabular}

Source: USDA correspondence to states

Table A2 Descriptive statistics overall and by work requirement status - control variables

\begin{tabular}{|c|c|c|c|c|c|c|c|}
\hline & \multicolumn{2}{|c|}{$\begin{array}{c}\text { FULL } \\
\text { SAMPLE } \\
(N=408)\end{array}$} & \multicolumn{2}{|c|}{$\begin{array}{c}\text { NO WR } \\
(N=225)\end{array}$} & \multicolumn{2}{|c|}{$\begin{array}{c}\text { WR } \\
(N=183)\end{array}$} & \multirow{2}{*}{$\begin{array}{l}\text { NO WR } \\
\text { V. WR } \\
p \text {-Value }\end{array}$} \\
\hline & Mean & Std. & Mean & Std. & Mean & Std. & \\
\hline TANF cases per 1,000 & 4.42 & 3.05 & 4.99 & 3.72 & 2.81 & 2.90 & $<0.001$ \\
\hline Medicaid expansion & 0.28 & 0.45 & 0.19 & 0.39 & 0.40 & 0.49 & 0.683 \\
\hline Unemployment rate & 6.34 & 2.16 & 7.64 & 1.78 & 4.74 & 1.38 & $<0.001$ \\
\hline State minimum wage & 7.66 & 0.96 & 7.58 & 7.76 & 1.07 & 1.06 & 0.064 \\
\hline Poverty ratio & 0.14 & 0.03 & 0.15 & 0.12 & 0.03 & 0.03 & $<0.001$ \\
\hline Fraction white & 0.69 & 0.16 & 0.67 & 0.71 & 0.16 & 0.15 & 0.012 \\
\hline Fraction black & 0.11 & 0.11 & 0.13 & 0.09 & 0.09 & 0.09 & $<0.001$ \\
\hline Fraction hispanic & 0.11 & 0.10 & 0.12 & 0.11 & 0.10 & 0.10 & 0.598 \\
\hline Fraction prime age adults & 0.40 & 0.02 & 0.40 & 0.39 & 0.02 & 0.02 & $<0.001$ \\
\hline Fraction with high school diploma & 0.68 & 0.03 & 0.68 & 0.69 & 0.03 & 0.03 & $<0.001$ \\
\hline Sex ratio (female to male) & 0.51 & 0.01 & 0.51 & 0.51 & 0.01 & 0.01 & $<0.001$ \\
\hline Medical cannabis dispensary & 0.26 & 0.44 & 0.24 & 0.03 & 0.28 & 0.03 & 0.374 \\
\hline Recreational cannabis dispensary & 0.03 & 0.18 & 0.00 & 0.00 & 0.07 & 0.02 & $<0.001$ \\
\hline "Must Access" PDMP & 0.17 & 0.38 & 0.12 & 0.02 & 0.25 & 0.03 & 0.001 \\
\hline
\end{tabular}

Notes: Data cover the period from 1/1/2010 through 12/31/2017. $p$-values are from two-sided $t$-tests for continuous measures and from chi-squared tests for dichotomous measures. 
Table A3 Comparing outcomes for state-years with and without work requirements

\begin{tabular}{|c|c|c|c|c|c|c|c|}
\hline & \multicolumn{2}{|c|}{ FULL SAMPLE } & \multicolumn{2}{|c|}{ NOWR } & \multicolumn{2}{|c|}{ WR } & \multirow{2}{*}{$\begin{array}{c}\text { NO WR } \\
\text { V. WR } \\
\text { p-Value }\end{array}$} \\
\hline & Mean & Std. & Mean & Std. & Mean & Std. & \\
\hline SSI applications per 10,000 & 33.43 & 13.97 & 38.10 & 0.98 & 27.69 & 0.78 & $<0.001$ \\
\hline SSI recipients per 10,000 & 11.19 & 3.84 & 12.20 & 0.29 & 9.95 & 0.20 & $<0.001$ \\
\hline SNAP recipiency & 0.13 & 0.04 & 0.14 & 0.00 & 0.12 & 0.00 & $<0.001$ \\
\hline SNAP recipiency - difficulty & 0.29 & 0.09 & 0.31 & 0.01 & 0.27 & 0.01 & $<0.001$ \\
\hline SNAP recipiency - low Income & 0.32 & 0.08 & 0.34 & 0.01 & 0.29 & 0.01 & $<0.001$ \\
\hline SSI recipiency & 0.02 & 0.01 & 0.02 & 0.00 & 0.02 & 0.00 & 0.002 \\
\hline SSI recipiency - difficulty & 0.22 & 0.07 & 0.23 & 0.00 & 0.20 & 0.00 & $<0.001$ \\
\hline SSI recipiency - low income & 0.06 & 0.03 & 0.07 & 0.00 & 0.06 & 0.00 & 0.276 \\
\hline
\end{tabular}

Notes: Data cover the period from $1 / 1 / 2010$ through $12 / 31 / 2017$. SSI applications per 10,000 population and SSI recipients per 10,000 population are based on the SAMWD data. SNAP and SSI recipiencies are from the CPS. All population measures are for the whole population. $p$-values are from two-sided $t$-tests.

Table A4 Averaged coefficients by period from Callaway and Sant'Anna (2021) event studies

\begin{tabular}{|c|c|c|c|c|c|c|c|c|}
\hline & (1) & (2) & (3) & (4) & (5) & (6) & (7) & (8) \\
\hline Period & $\begin{array}{c}\text { SSI } \\
\text { applications } \\
\text { per 10K }\end{array}$ & $\begin{array}{c}\text { SSI } \\
\text { recipients } \\
\text { per 10K }\end{array}$ & $\begin{array}{l}\text { SNAP } \\
\text { rate }\end{array}$ & $\begin{array}{l}\text { SSI } \\
\text { rate }\end{array}$ & $\begin{array}{c}\text { SNAP } \\
\text { rate - difficulty }\end{array}$ & $\begin{array}{c}\text { SNAP } \\
\text { rate - low } \\
\text { income }\end{array}$ & $\begin{array}{c}\text { SSI } \\
\text { rate - difficulty }\end{array}$ & $\begin{array}{c}\text { SSI } \\
\text { rate - low } \\
\text { income }\end{array}$ \\
\hline \multirow[t]{2}{*}{-7} & -0.496 & -0.451 & $0.014^{\star \star \star}$ & -0.002 & -0.020 & $0.0234^{\star}$ & 0.003 & 0.008 \\
\hline & (1.176) & $(0.743)$ & $(0.004)$ & $(0.002)$ & (0.193) & $(0.012)$ & $(0.035)$ & $(0.006)$ \\
\hline \multirow[t]{2}{*}{-6} & 0.883 & 0.174 & -0.006 & -0.001 & 0.020 & -0.013 & -0.044 & -0.016 \\
\hline & $(0.711)$ & $(0.223)$ & $(0.005)$ & $(0.001)$ & $(0.023)$ & $(0.016)$ & $(0.032)$ & $(0.008)$ \\
\hline \multirow[t]{2}{*}{-5} & -0.467 & -0.005 & 0.008 & 0.001 & -0.006 & 0.004 & 0.024 & 0.014 \\
\hline & $(0.561)$ & $(0.252)$ & $(0.005)$ & $(0.001)$ & $(0.036)$ & $(0.020)$ & $(0.026)$ & $(0.007)$ \\
\hline \multirow[t]{2}{*}{-4} & -0.414 & -0.032 & 0.007 & 0.000 & -0.033 & -0.005 & 0.020 & -0.001 \\
\hline & $(0.482)$ & $(0.217)$ & $(0.004)$ & $(0.001)$ & $(0.025)$ & $(0.016)$ & $(0.018)$ & $(0.008)$ \\
\hline \multirow[t]{2}{*}{-3} & -0.233 & -0.242 & -0.005 & 0.000 & 0.006 & 0.002 & -0.006 & -0.001 \\
\hline & $(0.486)$ & $(0.199)$ & $(0.006)$ & $(0.002)$ & $(0.025)$ & $(0.016)$ & $(0.022)$ & $(0.007)$ \\
\hline \multirow[t]{2}{*}{-2} & -0.004 & $0.353^{\star \star}$ & 0.000 & 0.000 & -0.006 & -0.004 & -0.016 & -0.009 \\
\hline & $(0.442)$ & $(0.179)$ & $(0.004)$ & $(0.001)$ & $(0.026)$ & $(0.014)$ & $(0.022)$ & $(0.008)$ \\
\hline \multirow[t]{2}{*}{-1} & 1.068 & 0.062 & -0.002 & -0.001 & -0.001 & -0.025 & 0.013 & 0.002 \\
\hline & (1.112) & $(0.334)$ & $(0.005)$ & $(0.001)$ & $(0.023)$ & $(0.019)$ & $(0.020)$ & $(0.007)$ \\
\hline \multirow[t]{2}{*}{0} & -0.027 & 0.161 & 0.001 & 0.000 & -0.002 & 0.011 & 0.018 & 0.009 \\
\hline & $(0.272)$ & $(0.150)$ & $(0.004)$ & $(0.001)$ & $(0.017)$ & $(0.018)$ & $(0.021)$ & $(0.007)$ \\
\hline \multirow[t]{2}{*}{1} & 0.459 & 0.102 & -0.001 & -0.001 & $-0.045^{\star}$ & $-0.039^{\star}$ & 0.002 & 0.005 \\
\hline & $(0.579)$ & $(0.280)$ & $(0.005)$ & $(0.001)$ & $(0.024)$ & $(0.022)$ & $(0.017)$ & $(0.007)$ \\
\hline \multirow[t]{2}{*}{2} & $1.693^{\star}$ & 0.375 & 0.003 & $-0.002^{\star}$ & $-0.070^{\star \star \star}$ & -0.020 & -0.002 & -0.006 \\
\hline & $(0.930)$ & $(0.446)$ & $(0.005)$ & $(0.001)$ & $(0.024)$ & $(0.020)$ & $(0.020)$ & $(0.006)$ \\
\hline \multirow[t]{2}{*}{3} & $2.451^{\star}$ & 0.791 & 0.007 & -0.002 & -0.050 & -0.023 & -0.018 & -0.004 \\
\hline & $(1.325)$ & $(0.662)$ & $(0.006)$ & $(0.002)$ & $(0.031)$ & $(0.028)$ & $(0.030)$ & $(0.012)$ \\
\hline 4 & $3.560^{\star}$ & 0.851 & 0.000 & 0.000 & -0.042 & -0.003 & 0.030 & -0.003 \\
\hline
\end{tabular}


Table A4 Continued

\begin{tabular}{|c|c|c|c|c|c|c|c|c|}
\hline \multirow[b]{2}{*}{ Period } & (1) & (2) & (3) & (4) & (5) & (6) & (7) & (8) \\
\hline & $\begin{array}{c}\text { SSI } \\
\text { applications } \\
\text { per 10K }\end{array}$ & $\begin{array}{l}\text { SSI } \\
\text { recipients } \\
\text { per 10K }\end{array}$ & $\begin{array}{l}\text { SNAP } \\
\text { rate }\end{array}$ & $\begin{array}{l}\text { SSI } \\
\text { rate }\end{array}$ & $\begin{array}{c}\text { SNAP } \\
\text { rate - difficulty }\end{array}$ & $\begin{array}{l}\text { SNAP } \\
\text { rate - low } \\
\text { income }\end{array}$ & $\begin{array}{c}\text { SSI } \\
\text { rate - difficulty }\end{array}$ & $\begin{array}{c}\text { SSI } \\
\text { rate - low } \\
\text { income }\end{array}$ \\
\hline & $(1.861)$ & $(0.995)$ & $(0.008)$ & $(0.001)$ & $(0.044)$ & $(0.037)$ & $(0.028)$ & $(0.008)$ \\
\hline \multirow[t]{2}{*}{5} & 1.444 & 0.383 & -0.005 & -0.001 & -0.006 & -0.030 & $0.049^{*}$ & 0.009 \\
\hline & $(1.970)$ & $(0.940)$ & $(0.011)$ & $(0.001)$ & $(0.043)$ & $(0.043)$ & $(0.028)$ & $(0.013)$ \\
\hline \multirow[t]{2}{*}{6} & 4.854 & 2.248 & 0.004 & -0.001 & $-0.108^{\star}$ & -0.070 & 0.014 & -0.022 \\
\hline & (3.471) & (2.673) & $(0.013)$ & $(0.002)$ & $(0.056)$ & $(0.043)$ & $(0.048)$ & $(0.014)$ \\
\hline
\end{tabular}

Notes: Underlying data come from the SAMWD and CPS (2010-2017). Outcomes in Columns 1 and 2 are measured per 10,000 population; Outcomes in Columns 3-8 are rates. All regressions include state and year fixed effects. Average Treatment Effects on the Treated (ATT) are measured by Period (year) relative to the period in which work requirements were implemented (Period $=0$ ). ATTs are calculated by running event studies separately for each group as defined by year of work requirement implementation. Leads and lags are then averaged, weighting by the share of states in each group. Standard errors clustered at the state level and reported in parentheses.

${ }^{\star \star *} p<0.01,{ }^{\star \star} p<0.05,{ }^{\star} p<0.1$.

Table A5 Weighted treatment - overall samples

\begin{tabular}{lcccc}
\hline \multirow{2}{*}{ Variables } & $\mathbf{( 1 )}$ & $\mathbf{( 2 )}$ & $\mathbf{( 3 )}$ & $\mathbf{( 4 )}$ \\
\cline { 2 - 5 } & $\begin{array}{c}\text { SSI } \\
\text { applications } \\
\text { per 10K }\end{array}$ & $\begin{array}{c}\text { SSI } \\
\text { recipients } \\
\text { per 10K }\end{array}$ & $\begin{array}{c}\text { SNAP } \\
\text { recipiency }\end{array}$ & $\begin{array}{c}\text { SSI } \\
\text { recipiency }\end{array}$ \\
\hline Any work requirement & -0.002 & 0.333 & -0.005 & -0.000 \\
Weighted by counties affected & $(0.545)$ & $(0.258)$ & $(0.003)$ & $(0.001)$ \\
Weighted by ABAWD population & -1.125 & -0.271 & $-0.013^{\star}$ & -0.001 \\
Weighted by non-exempted & $(1.304)$ & $(0.497)$ & $(0.007)$ & $(0.001)$ \\
ABAWD population & -1.985 & 0.311 & $-0.037^{\star \star}$ & -0.002 \\
& $(3.245)$ & $(1.242)$ & $(0.018)$ & $(0.004)$ \\
& -2.300 & 0.444 & $-0.041^{\star *}$ & -0.003 \\
\hline
\end{tabular}

Notes: Underlying data come from the SAMWD and CPS (2010-2017). Each cell represents a separate regression. Outcomes in Columns 1 and 2 are measured per 10,000 population; Outcomes in Columns 3 and 4 are rates. All regressions include state and year fixed effects. Standard errors clustered at the state level and reported in parentheses.

${ }^{\star \star \star} p<0.01,{ }^{\star \star} p<0.05,{ }^{\star} p<0.1$. 
Table A6 Weighted treatment - subgroups

\begin{tabular}{lcccc}
\hline & $\mathbf{( 1 )}$ & $\mathbf{( 2 )}$ & $\mathbf{( 3 )}$ & $\mathbf{( 4 )}$ \\
\cline { 2 - 5 } Variables & SNAP & SNAP & SSI & SSI \\
& rate - difficulty & rate - low income & rate - difficulty & rate - low income \\
\hline Any work requirement & -0.013 & -0.007 & -0.001 & 0.004 \\
Weighted by counties affected & $(0.012)$ & $(0.011)$ & $(0.009)$ & $(0.005)$ \\
& -0.030 & -0.015 & -0.010 & 0.006 \\
Weighted by ABAWD population & $(0.025)$ & $(0.027)$ & $(0.020)$ & $(0.011)$ \\
Weighted by non-exempted ABAWD & -0.081 & -0.054 & -0.019 & 0.013 \\
population & $(0.069)$ & $(0.067)$ & $(0.049)$ & $(0.028)$ \\
& -0.091 & -0.067 & -0.029 & 0.001 \\
\hline
\end{tabular}

Notes: Underlying data come from the SAMWD and CPS (2010-2017). Each cell represents a separate regression. Outcomes in Columns 1 and 2 are measured per 10,000 population; Outcomes in Columns 3 and 4 are rates. All regressions include state and year fixed effects. Standard errors clustered at the state level and reported in parentheses.

${ }^{\star \star \star} p<0.01,{ }^{\star \star} p<0.05,{ }^{\star} p<0.1$.

Figure A1 SSA applications and recipients per 10,000 population by year.

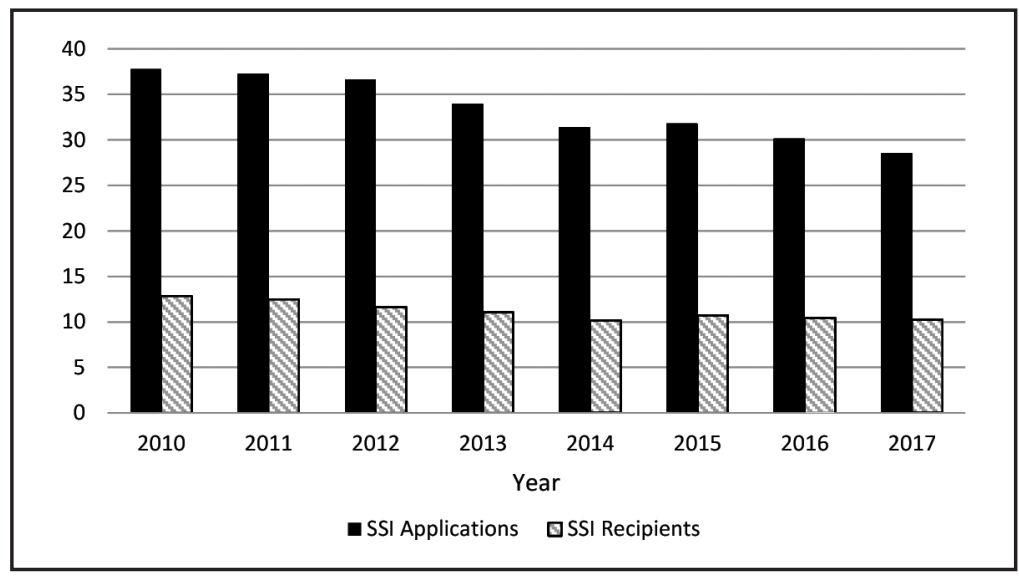

Notes: Data are from the SAMWD.

Figure A2 Probability of SNAP recipiency over time.

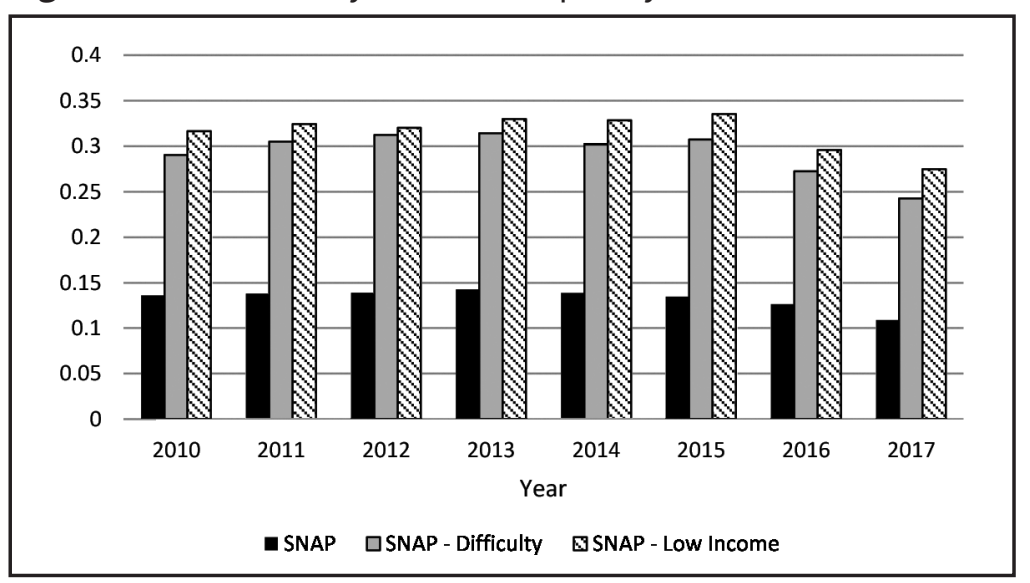

Notes: Data are from the CPS. SNAP - Difficulty includes all individuals reporting a disability based on the six-part monthly difficulty question and the annual work limitation question. SNAP - Low income includes individuals earning $<150 \%$ of the federal poverty line. 
Figure A3 Probability of SSI recipiency over time.

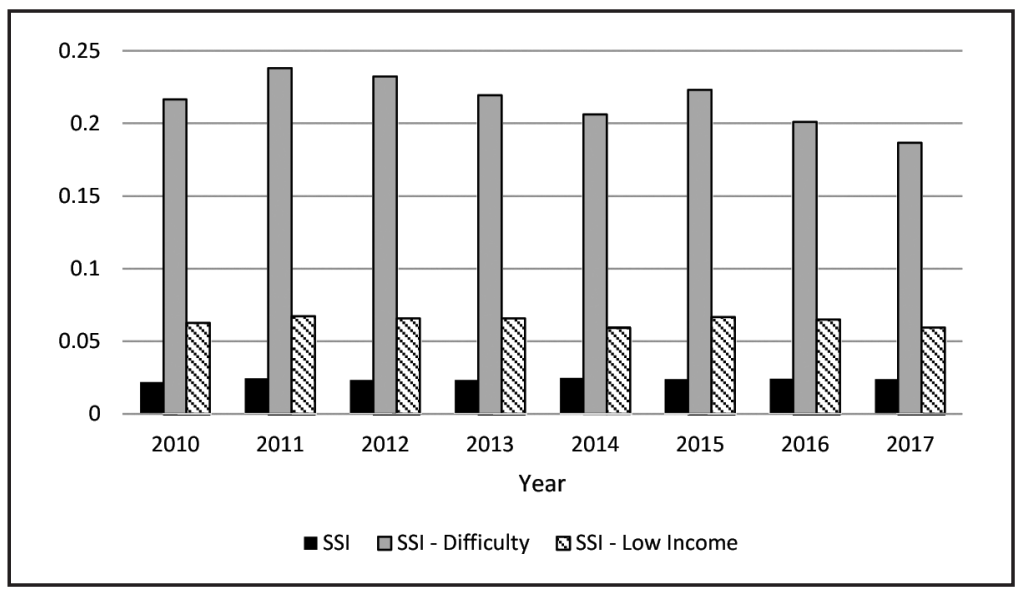

Notes: Data are from the CPS. SSI - Difficulty includes all individuals reporting a disability based on the six-part monthly difficulty question and the annual work limitation question. SSI - Low income includes individuals earning $<150 \%$ of the federal poverty line.

Figure A4 Event studies.

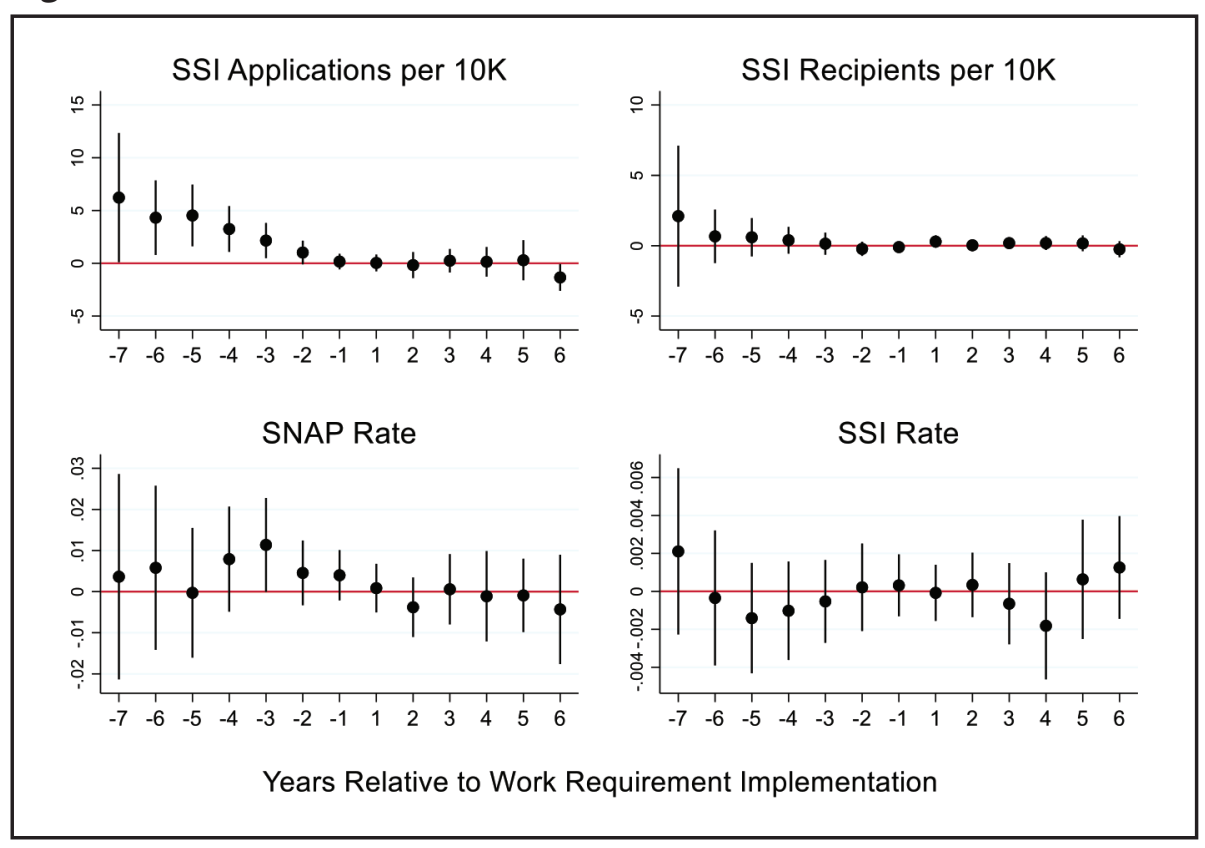

Notes: Event studies are run including the full range of leads and lags available in the data and state and year fixed effects. Policy implementation occurs at time $t=0$. Virginia and West Virginia gained and reversed work requirements during the sample period and are omitted from the event study analysis. Standard errors are clustered at the state-level. 95\% confidence intervals are reported. 
Figure A5 Event studies - Difficulty or low income.

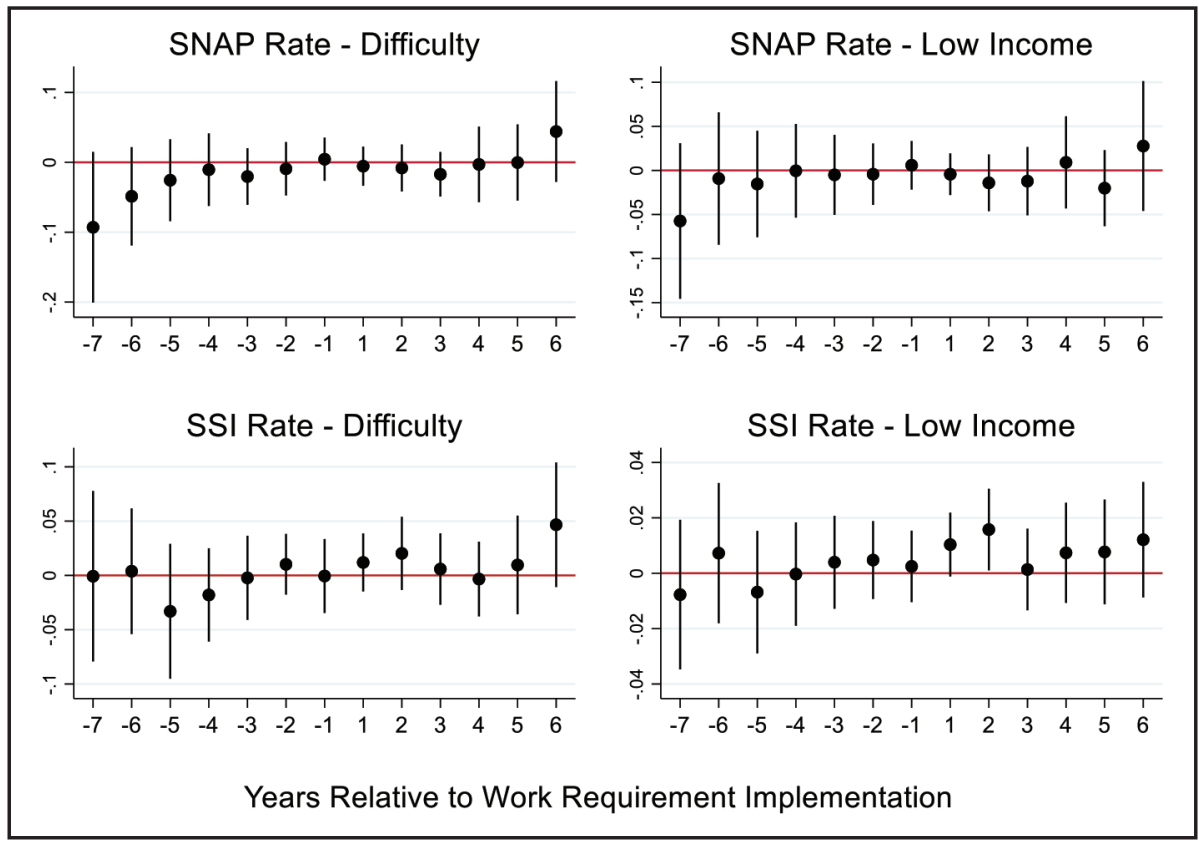

Notes: Event studies are run including the full range of leads and lags available in the data and state and year fixed effects. Policy implementation occurs at time $t=0$. Virginia and West Virginia gained and reversed work requirements during the sample period and are omitted from the event study analysis. Standard errors are clustered at the state-level. 95\% confidence intervals are reported.

Figure A6 ATT by treatment group - Overall.

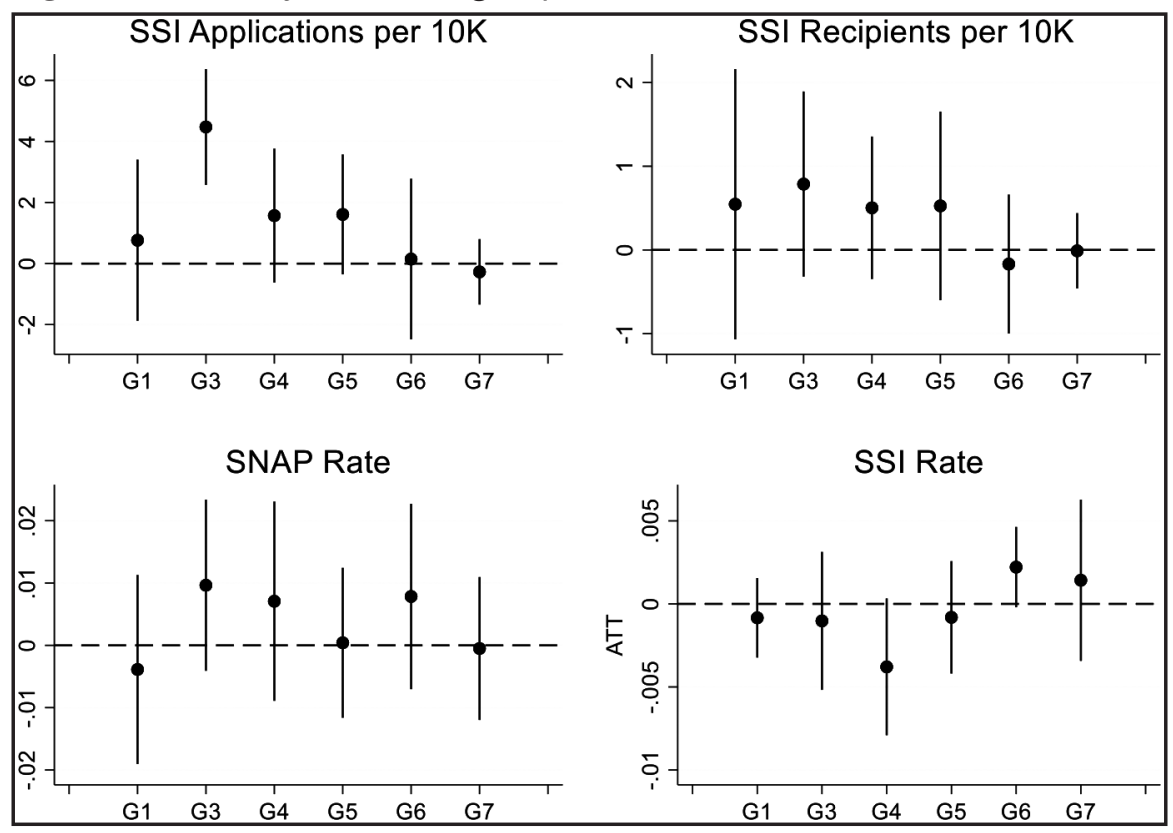

Notes: Average Treatment Effects on the Treated (ATT) are graphed treatment group, as defined by the year the work requirement was implemented. ATTs are calculated by running event studies separately for each group as defined by year of work requirement implementation. Leads and lags are then averaged, weighting by the share of states in each group, before being aggregated to calculate the group-specific treatment effect. Virginia and West Virginia gained and reversed work requirements during the sample period and are omitted from the event study analysis. Underlying regressions control for state and year fixed effects with standard errors clustered at the state level. 
Figure A7 ATT by treatment group-Overall.

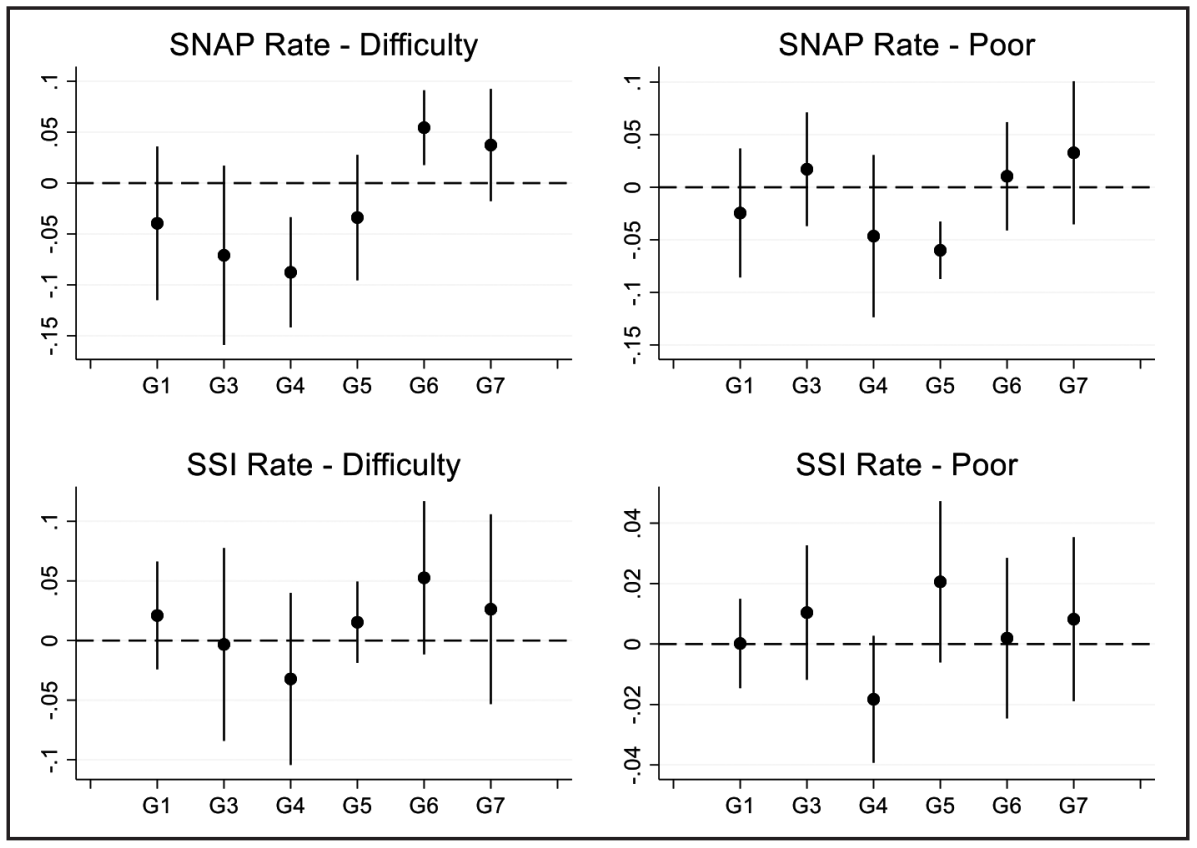

Notes: Average Treatment Effects on the Treated (ATT) are graphed treatment group, as defined by the year the work requirement was implemented. ATTs are calculated by running event studies separately for each group as defined by year of work requirement implementation. Leads and lags are then averaged, weighting by the share of states in each group, before being aggregated to calculate the group-specific treatment effect. Virginia and West Virginia gained and reversed work requirements during the sample period and are omitted from the event study analysis. Underlying regressions control for state and year fixed effects with standard errors clustered at the state level. 


\section{Appendix B: CPS Disability-Related Questions}

Disability Six-Question Sequence (Monthly):

1. Is anyone deaf or does anyone have serious difficulty hearing?

2. Is anyone blind or does anyone have serious difficulty seeing even when wearing glasses?

3. Because of a physical, mental, or emotional condition, does anyone have serious difficulty concentrating, remembering, or making decisions?

4. Does anyone have serious difficulty walking or climbing stairs?

5. Does anyone have difficulty dressing or bathing?

6. Because of a physical, mental, or emotional condition, does anyone have difficulty doing errands alone such as visiting a doctor's office or shopping?

Work Limitation Question (March Supplement):

1. (Do you/Does anyone in the household) have a health problem or disability which prevents (you/them) from working or which limits the kind or amount of work (you/they) can do? 